\title{
Cell-Derived Hexameric $\beta$-Amyloid: A Novel Insight Into Composition, Self-Assembly and Nucleating Properties
}

\section{Devkee Vadukul}

Université Catholique de Louvain

\section{Céline Vrancx}

Université Catholique de Louvain

\section{Pierre Burguet}

University of Liège

\section{Sabrina Contino}

Université Catholique de Louvain

\section{Nuria Suelves}

Université Catholique de Louvain

\section{Louise Serpell}

University of Sussex

\section{Loïc Quinton}

\section{University of Liège}

Pascal Kienlen-Campard ( $\sim$ pascal.kienlen-campard@uclouvain.be )

Université Catholique de Louvain

\section{Research Article}

Keywords: Alzheimer's disease, hexameric, Molecular

Posted Date: December 17th, 2020

DOl: https://doi.org/10.21203/rs.3.rs-129253/v1

License: (c) (1) This work is licensed under a Creative Commons Attribution 4.0 International License. Read Full License 


\title{
Cell-derived hexameric $\beta$-amyloid: a novel insight into composition, self- assembly and nucleating properties
}

Devkee M. Vadukul ${ }^{1 \dagger}, 2$, Céline Vrancx ${ }^{1}$, Pierre Burguet ${ }^{3}$, Sabrina Contino ${ }^{1}$, Nuria Suelves ${ }^{1}$, Louise C Serpel1 ${ }^{4}$, Loïc Quinton ${ }^{3}$ and Pascal Kienlen-Campard ${ }^{*}$

\author{
${ }^{1}$ Alzheimer Research Group, Molecular and Cellular division (CEMO), Institute of Neuroscience, Université \\ catholique de Louvain, Brussels, Belgium. \\ ${ }^{2}$ Molecular Sciences Research Hub (MSRH), Department of Chemistry, Imperial College London, London, UK \\ ${ }^{3}$ Mass Spectrometry Laboratory, MolSys Research Unit, University of Liège, Liège, Belgium \\ ${ }^{4}$ Sussex Neuroscience, School of Life Sciences, University of Sussex, Falmer, Brighton, East Sussex BN1 9QG, \\ UK \\ ${ }^{\dagger}$ Current affiliation \\ *Corresponding author: \\ Pascal Kienlen-Campard (pascal.kienlencampard@uclouvain.be)
}

\begin{abstract}
A key hallmark of Alzheimer's disease (AD) is the extracellular deposition of amyloid plaques composed primarily of the amyloidogenic amyloid- $\beta(\mathrm{A} \beta)$ peptide. The $\mathrm{A} \beta$ peptide is a product of sequential cleavage of the Amyloid Precursor Protein (APP), the first step of which gives rise to a Cterminal Fragment (C99). Cleavage of C99 by $\gamma$-secretase activity releases A $\beta$ of several lengths and the $A \beta 42$ isoform in particular has been identified as being neurotoxic. The misfolding of $A \beta$ leads to subsequent amyloid fibril formation by nucleated polymerisation. This requires an initial and critical nucleus for self-assembly. Here, we identify and characterise the composition and self-assembly properties of cell-derived hexameric $A \beta 42$ and show its nucleating properties which are dependent on the $A \beta$ monomer availability. Identification of nucleating assemblies that contribute to self-assembly in this way may serve as therapeutic targets to prevent the formation of toxic oligomers.
\end{abstract}




\section{$\underline{\text { Introduction }}$}

Alzheimer's disease (AD) is a neurodegenerative disease characterised by the deposition of extracellular amyloid plaques in the brain which are primarily composed of the self-assembled amyloid$\beta$ (A $\beta$ ) peptide[1]. The self-assembly process of $A \beta$ has been the focus of much research, however, it is still unclear how this relates to disease pathology. $A \beta$ is a product of sequential cleavage of the Amyloid Precursor Protein (APP) in the amyloidogenic pathway where APP is first cleaved by $\beta$-secretase at the N-terminus of A $\beta$. The two products of this are soluble APP- $\beta$ (sAPP $\beta$ ) and a C-terminal fragment (CTF) consisting of 99 amino acids (C99). C99 is further cleaved by $\gamma$-secretase beginning with a proteolytic cut at the $\varepsilon$ site to free the C-terminal APP intracellular domain (AICD) and release A $\beta$ of varying lengths ranging from $A \beta 49-38[2-4]$.

Although extracellular $\mathrm{A} \beta$ plaques found in $\mathrm{AD}$ brains are primarily composed of highly ordered cross$\beta$ mature amyloid fibrils[5-7], soluble forms of $A \beta$ have shown a much greater correlation with cognitive decline and neurodegeneration in $\mathrm{AD}$ patients[8,9]. Due to this, it is now widely accepted that pre-fibrillar spherical/globular $\mathrm{A} \beta$ oligomers are neurotoxic entities. In particular, several $\mathrm{A} \beta 42$ oligomers of different assembly sizes and conformations have been identified as being cytotoxic[7,10$18]$.

Oligomers are formed as intermediary assemblies during amyloid formation, the mechanism of which is via nucleated polymerisation[19]. There is first the nucleation or lag phase where the monomer precursor is either in an unfolded, partially folded or natively folded state and undergoes usually unfavourable self-association to form nuclei that are critical for further self-assembly [20]. This critical nucleus is defined as the smallest assembly size that grows faster by the addition of monomers, than dissociates back to smaller assemblies including monomers[21]. Once the critical nucleus has been formed, there is a rapid formation of fibrils by the addition of monomers. This is the elongation phase and fibril formation in this way is known as primary nucleation. The formation of these nuclei is therefore crucial in the generation of amyloid and the identification of these structures will ultimately aid our understanding of amyloid assembly and pathology.

One likely nucleus of A $\beta 42$ assembly has been suggested to be a hexameric assembly[20,22-26]. It has been shown that the formation of hexameric $A \beta 42$ is an early event in the self-assembly pathway $[23,24,27,28]$ and the identification of several multimers of hexamers e.g. A $\beta$ derived diffusible ligands (ADDLs), $A \beta^{*} 56$ and globulomers provide a compelling argument that the hexamer is the basic building block for the formation of toxic oligomers[15,29]. The majority of these studies investigating the role of hexameric $\mathrm{A} \beta 42$ as a nucleus for self-assembly make use of synthetic peptides which are greatly advantageous due to being readily available at high concentrations necessary for biophysical and structural characterisation. However, the true cellular environment and processing of C99 to release $\mathrm{A} \beta$ cannot be mimicked using these synthetic peptides. 
Furthermore, familial $\mathrm{AD}$ (FAD) causing mutations within the $\mathrm{A} \beta$ sequence, which are also in the extracellular domain of the $\mathrm{C} 99$ sequence, have been shown to have a higher aggregation propensity in previous studies using synthetic and recombinant proteins[30-38]. It is not yet understood whether these FAD mutations which promote self-assembly, increase overall $\mathrm{A} \beta$ production, and/or change biochemical properties, also promote/enhance the formation of hexameric $A \beta$ assemblies.

Here, by transfection of Chinese Hamster Ovarian (CHO) cells, we identify the formation of hexamers in $\mathrm{A} \beta$ enriched conditions. We also identify for the first time, the formation of hexameric $\mathrm{A} \beta$ in $\mathrm{CHO}$ transfected with the Flemish (A21G), Dutch (E22Q), Italian (E22K), Arctic (E22G) and Iowa (D23N) FAD causing mutations[39-42]. We have isolated cell-derived hexameric $A \beta$ assemblies and assessed their assembly and nucleating properties using complementary techniques including Mass Spectroscopy, Thioflavin T (ThT) fluorescence and immunoblotting. We identify these cell-derived A $\beta$ hexamers as $A \beta 42$ assemblies which are major contributing nuclei for the self-assembly of $A \beta$ monomers. This nucleating propensity is much more pronounced on monomeric $A \beta 42$ than $A \beta 40$ and is highly dependent on the concentration of available monomers. Furthermore, we show for the first time in a cellular context that the formation of this hexamer is an inherent property of the A $\beta 42$ peptide and its self-assembly propensity, as a self-assembly impaired primary sequence variant of $A \beta 42$ does not form hexamers. The identification of assemblies nucleating $A \beta$ self-assembly in this way provides potential therapeutic targets to prevent oligomer-induced neurotoxicity.

\section{$\underline{\text { Results }}$}

\section{$\mathrm{A} \beta$ assembly profile in $\mathrm{CHO}$ cells: Identification of hexameric $\mathrm{A} \beta$}

Although A $\beta$ self-assembly has been extensively studied with synthetic peptides, less is known about the assembly of $A \beta$ peptides produced in a cellular context. As C99 processing precedes $A \beta$ release in physiology, we first assessed the $\mathrm{A} \beta$ assembly profile in $\mathrm{CHO}$ cells transfected with the human $\mathrm{C} 99$ sequence affixed with the signal peptide of the full-length APP in a pSVK3 plasmid backbone. Cell lysates and media of $\mathrm{CHO}$ cells were harvested 48 hours after transfection and the $\mathrm{A} \beta$ profile was assessed by western blotting and detected using the monoclonal human specific anti-A $\beta$ W0-2 antibody (Figure 1A). In line with what has previously been shown by our group, we confirm that cells transfected with C99 produce a detectable band corresponding to an $\mathrm{A} \beta$ assembly size of $\sim 28 \mathrm{kDa}$; the theoretical size of an A 342 hexamer [43]. Detection with the anti-Cter antibody against the C-terminal of APP did not identify these bands, consolidating these assemblies are likely to be $\mathrm{A} \beta$ and do not contain the CTF of C99 (Supplemental Figure S1). Furthermore, as the band was not detected in the Empty Plasmid (EP) condition, we are confident that the hexamer is not a product of the transfection protocol. Whilst only $\mathrm{A} \beta$ hexamers were detected in the cell lysates of these cells, monomers, dimers, trimers and hexamers were detected in the media confirming that in our cellular model, C99 is cleaved to release A $\beta$ detectable 
both intra- and extracellularly (Figure 1A). Additionally, we also assessed the $\mathrm{A} \beta$ profile of cells transfected with the $A \beta 40$ and $A \beta 42$ sequences affixed with the APP signal peptide (referred to as $C 40$ and $\mathrm{C} 42$ respectively) to understand whether the formation of this hexamer in a cellular context was related to one or both of these $A \beta$ isoforms (Figure 1B). We do not identify a hexameric band in the cell lysates or culture media of $\mathrm{C} 40$ transfected $\mathrm{CHO}$ cells, which would be $\sim 26 \mathrm{kDa}$ in size, in line with the preferential formation of hexamers by $\mathrm{A} \beta 42$ previously shown with synthetic peptides[23]. The identification of a hexameric band both intra- and extracellularly in C42 transfected CHO cells suggests that 1) formation of hexameric $A \beta$ is irrespective of whether there is first the processing of the C99 fragment and 2) cell-derived hexamer formation is likely to be an intrinsic property of the A $\beta 42$ sequence itself, as has been demonstrated previously with synthetic peptides[23,26,27].

To link the formation of hexameric $A \beta$ assembly to disease related conditions, we investigated the $A \beta$ profile in $\mathrm{CHO}$ cells transfected with the $\mathrm{C} 99$ sequence containing the $\mathrm{A} 21 \mathrm{G}, \mathrm{E} 22 \mathrm{Q}, \mathrm{E} 22 \mathrm{~K}, \mathrm{E} 22 \mathrm{G}$ and D23N FAD mutations. In Figure 1C (left panel), we show that in CHO cells transfected with the C99 sequence containing these mutations, there is the detection of hexameric $\mathrm{A} \beta$ in cell lysates. The hexamer is also detected in the media of A21G, E22K and D23N expressing cells (Figure 1C, right panel). In particular, the $\mathrm{D} 23 \mathrm{~N}$ mutation shows a much more pronounced hexamer formation compared to any other mutant. This was confirmed by quantification of hexamer production in cell lysates normalised to the C99 signal (Figure 1D) which shows that the D23N mutant generates significantly more hexameric $\mathrm{A} \beta$ than the wild-type $\mathrm{C} 99(\mathrm{p}=<0.001)$, while all other mutants displayed similar levels of hexamer formation. Together, this demonstrates that formation of hexameric $A \beta$ is occurring in several ADrelated conditions.

From these results, we can conclude that the formation of a hexameric assembly is a common feature in $A \beta$ enriched conditions as well as in $A D$ related $A \beta$ mutations where amyloid formation is accelerated.

\section{Isolation and composition of cell-derived $\mathrm{A} \beta$}

As the aim of this study was to characterise the formation, self-assembly and nucleating properties of the hexamer, we next optimised the isolation of media derived hexameric $\mathrm{A} \beta$. We have focussed here on $A \beta$ material in the media as we hypothesise that the self-assembly leading to the deposition of extracellular amyloid plaques is likely dependent on the presence of this hexamer in the extracellular space. To isolate the $\mathrm{A} \beta$ hexamer, $\mathrm{CHO}$ cells were transfected with $\mathrm{C} 42$ or $\mathrm{C} 99$ for 48 hours and media was immunoprecipitated using the W0-2 antibody. This was then separated using the Gel Eluted Liquid Fraction Entrapment Electrophoresis $\left(\mathrm{GELFrEE}^{\circledR}\right) 8100$ system. Briefly, as with SDS-PAGE, this system separates the peptide by size with the added advantage of collecting the assembly size of interest as a liquid fraction. Shown in Figure $2 \mathrm{~A}$, we confirm by western blotting the isolation of hexameric A $\beta$ from the media of $\mathrm{CHO}$ cells transfected with $\mathrm{C} 42$ and $\mathrm{C} 99$ in fraction 5 only (C42 fraction 1-4 shown 
in Supplemental Figure S2). By isolating and characterising hexamers from both conditions, we are able to assess whether processing affects the self-assembly and nucleating properties of $A \beta$ hexamers. We are also able to isolate $C 99$-derived $A \beta$ monomers in fraction 1, however, as lower molecular weight assemblies were not detectable in $\mathrm{CHO}$ cells transfected with $\mathrm{C} 42$, even when samples were harvested at earlier time points after transfection (Supplemental Figure S3), this was not possible for C42 transfected $\mathrm{CHO}$ cells. Considering the highly hydrophobic and aggregation prone nature of the A $\beta 42$ sequence, it is unsurprising that we cannot detect lower molecular weight assemblies which, if present, are likely too low in concentration to detect by western blotting.

To identify the isoform of $\mathrm{A} \beta$ in the $\mathrm{C} 42$ and C99-derived hexameric assemblies, we carried out dot blotting using anti-A $\beta 42$ and anti-A $\beta 40$ specific antibodies (Figure $2 \mathrm{~B}$ ) with synthetic preparations of $\mathrm{A} \beta 40$ and $\mathrm{A} \beta 42$ as positive controls. Dot blotting with W0-2 (Figure 2B, left panel) antibody was used to confirm the presence of the proteins. Our results clearly show the A $\beta 42$ specific antibody binds to hexameric assemblies from both conditions (Figure 2B, right panel) whereas no signal is seen for either hexamer with the $A \beta 40$ specific antibody (Figure $2 B$, middle panel), thus confirming the $A \beta$ hexamers are $\mathrm{A} \beta 42$ assemblies.

The formation of a hexameric assembly is an inherent property of the Aß42 peptide due to selfassembly propensity

The preferential formation of hexameric $A \beta$ has been suggested to be linked to the $C$-terminus of $A \beta 42$ and its self-assembly propensity[23]. To assess this in our cellular model, $\mathrm{CHO}$ cells were transfected with an assembly-impaired variant of the $\mathrm{C} 42$ sequence, $\mathrm{vC} 42$, and the $\mathrm{A} \beta$ profile was assessed by western blotting and detection with the W0-2 antibody (full primary sequence can be found in Supplemental Table S1). This is the same sequence that has been previously reported and thoroughly characterised as being self-assembly impaired despite only a two amino acid difference (F19S and G37D) compared to the wild-type A 442 sequence[44]. Figure 3 demonstrates that $\mathrm{CHO}$ cells transfected with this variant produced only dimers in the cell lysates and no detectable assemblies in the media. The lack of a hexameric assembly confirms the importance of self-assembly in the formation of this structure and its direct link to $A \beta 42$ aggregation propensity.

\section{Cell-derived Aß42 hexamer formation is a direct consequence of $\mathrm{A} \beta 42$ primary sequence}

As both monomeric and hexameric $\mathrm{A} \beta$ were detected and isolated from $\mathrm{C} 99$ transfected cells, we next questioned whether the C99-derived $A \beta$ monomers isolated in Fraction 1 (Figure 2A) were able to assemble into hexamers. No assembly of the $A \beta$ monomer isolated from the media of the C99 transfected cells was seen by western blotting over 48 hours, the time in which we see hexamer presence in the cell lysates and media of $\mathrm{C} 42$ and C99 transfected CHO cells (Figure 4A). Electro- 
chemiluminescence immunoassay (ECLIA) measurements, which provide quantitative analysis of monomeric $\mathrm{A} \beta$, were performed on the media of $\mathrm{C} 99$ transfected $\mathrm{CHO}$ cells (Figure 4B) before immunoprecipitation for $A \beta$ and confirmed that $A \beta 40$ was in high abundance $(80.9 \mathrm{pg} / \mathrm{mL})$ whereas very low concentrations of $A \beta 42(1.3 \mathrm{pg} / \mathrm{mL})$ were detected. This provided early indications that the monomer detected by western blot (Figure 1A) is likely to be $\mathrm{A} \beta 40$. Analysis of the isolated monomer fraction by mass spectrometry (Figure 4C) revealed that, in line with the reduced self-assembly properties reported in the literature[45], only the A $\beta 40$ sequence was identified in this sample. Finally, we have confirmed by western blotting that $\mathrm{A} \beta 40$ is unable to form hexamers even in a cellular context, as $\mathrm{CHO}$ cells transfected with $\mathrm{C} 40$ do not produce a detectable band for this assembly in either cell lysates or media (Figure 1B). qPCR data consolidated that this was not due to low transfection efficiency (Supplemental S4).

Together, these data show for the first time from cell-derived material that $A \beta 40$ does not readily form hexameric assemblies, which in turn reinforces that the primary sequence of A $\beta 42$ and its resultant selfassembly properties are determining factors in the formation of a hexameric assembly.

\section{Isolated hexameric Aß42 does not self-assemble into higher molecular weight assemblies}

In order to establish the self-assembly properties of the isolated hexameric $A \beta 42$ derived from media of C42 and C99 transfected CHO cells (Fraction 5 shown in Figure 2A), we first carried out a ThT fluorescence assay as a measure of fibril formation. $150 \mu \mathrm{M}$ of hexameric $\mathrm{A} \beta$ was incubated with $20 \mu \mathrm{M}$ ThT and fluorescence was monitored over 48 hours. Figure 5A shows that over this time course, there is no increase in fluorescence seen which suggests that the hexameric assembly does not form fibrils in the timeframe of our experiment. To further consolidate this and detect any pre-fibrillar assemblies that may not bind to the ThT dye, western blotting was carried out on the same samples at several time points (Figure 5B and C). Detected by the W0-2 antibody, we see there are no higher molecular weight assemblies at longer time points and only the hexameric assembly is detected for C42-derived hexamers. This also confirms that there is no degradation or disassembly of the peptide. However, although C99-derived A 342 hexamers do not assemble into higher molecular weight assemblies, monomers are detected with increasing intensities over time. This suggests that in the C99 transfected conditions where processing is taking place, the hexamer is less stable and does disassemble into monomers. This is reflective of the dynamic nature of self-assembly, particularly in the formation of a critical nucleus. As we have identified the hexamers to be only composed of the $A \beta 42$ isoform, these data also allow us to conclude that the monomers detected from the disassembled C99-derived hexamers are likely to be $\mathrm{A} \beta 42$ monomers. Combined, these data show no further self-assembly of hexameric $\mathrm{A} \beta$ assemblies derived from both C42 and C99 in our experimental conditions. We therefore conclude that these cell-derived hexameric assemblies have similar self-assembly properties in our experimental conditions; the hexamer on its own does not self-assemble into higher molecular weight assemblies, 
however, the stability of C99-derived $\mathrm{A} \beta 42$ hexamers is weaker than that of C42-derived $\mathrm{A} \beta 42$ hexamers.

\section{Hexameric Aß42 preferentially nucleates self-assembly of Aß42 monomers}

Finally, we assessed the nucleating properties of isolated $\mathrm{A} \beta 42$ hexamers by seeding monomeric synthetic $A \beta 42$ (mAß42) with increasing amounts of isolated $C 42$ and C99-derived $A \beta 42$ hexamers (Figure 6A). mAß42 was prepared as previously described [44] and diluted to a working stock concentration of $50 \mu \mathrm{M}$. ThT fluorescence of $\mathrm{mA} \beta 42$ without any seeding (Supplemental Figure S5) shows a lag phase (0-4hours) and an elongation phase (4-24hours), as has been previously shown[44,46,47]. The concentration of hexamer used for seeding was a percentage of the mA $\beta 42$ concentration and the final solution was incubated with $20 \mu \mathrm{M}$ ThT dye. As the nucleating effects of the hexamer are expected to be in the early stages of assembly, ThT fluorescence was monitored for 4 hours and normalised for each condition to itself at $\mathrm{T} 0$ as a representation of increased fluorescence at each time point (Figure 6A).

The addition of 5\% (light pink line) and 10\% (dark pink line) C42-derived hexamer immediately results in an increase in fluorescence intensity, as does the addition of 5\% (light green line) C99-derived A $\beta 42$ hexamer. This suggests increased self-assembly kinetics in the early stages of aggregation for these conditions, however, $10 \%$ (dark green line) addition of $\mathrm{C} 99$-derived $\mathrm{A} \beta 42$ hexamer results in a similar ThT fluorescence as $\mathrm{mA} \beta 42$ alone (black line). This was further consolidated by assessing the range of assembly sizes present at $\mathrm{T} 0$ and 2 hours after hexamer addition by western blotting using the W0-2 antibody (Figure 6C). We see that even at T0, mA 342 seeded with 5 and 10\% C42-derived hexamers show the formation of higher molecular weight assemblies which are not present in the mA $\beta 42$ only sample. By 2 hours, both seeded conditions show the formation of a larger range of higher molecular weight assemblies which migrate as a smear as well as fibrils 'stuck' in the well of the gel, whilst mA $\beta 42$ without seeding displays bands corresponding to monomers, dimers and trimers only. Western blotting for $\mathrm{mA} \beta 42$ seeded with C99-derived $\mathrm{A} \beta 42$ hexamers (Figure $6 \mathrm{C}$ ) also revealed similar trends to that of C42-derived hexamer seeding where higher molecular weight assemblies were detected at $\mathrm{T} 0$ in the seeded conditions, and by 2 hours fibrils were 'stuck' in the wells of the gel. As we have identified both hexamers to be $A \beta 42$, this is unsurprising. Interestingly, in contrast to what was seen with the ThT fluorescence, $10 \%$ addition of C99-derived A 342 hexamers does result in the formation of higher molecular weight assemblies and fibrils being stuck in the well by 2 hours, perhaps suggesting the formation of ThT negative aggregates. Combined, this supports the hypothesis of the hexamer as a nucleus for self-assembly.

For a more robust analysis of the nucleating effects in the early stages of self-assembly, we have calculated the gradient of the graph for each condition from $0-1$ hour as an indication of assembly kinetics (Figure 6D). The addition of 5\% C42 and C99-derived hexamer significantly increases the 
gradient of the graph $(0.51 \mathrm{AU} \pm 0.03 \mathrm{SEM}, 0.4 \mathrm{AU} \pm 0.05 \mathrm{SEM}$ respectively, $\mathrm{p}=<0.01)$ compared to $\mathrm{mA} \beta 42$ alone ( $0.16 \mathrm{AU} \pm 0.05 \mathrm{SEM})$. Although an increase was also seen with $10 \% \mathrm{C} 42$ hexamer $(0.32$ $\mathrm{AU} \pm 0.1 \mathrm{SEM}$ ), this was not significant. This is likely due to the fact that the nucleating potential of the cell-derived C42 hexamer is dependent on the available monomers in solution. Furthermore, the same increase in early assembly kinetics was not seen with $10 \%$ C99-derived A $\beta 42$ seeding $(0.1 \mathrm{AU}$ $\pm 0.06 \mathrm{SEM})$. This might be due to the difference in stability of the C99-derived $\mathrm{A} \beta$ hexamer; as it disassembles into monomers with time (Figure 4C), the concentration of monomers continues to dominate the solution population and there is perhaps not enough hexamer in solution to nucleate selfassembly which may indicate a threshold concentration is required before nucleating effects can be seen.

Finally, we also assessed the nucleating properties of both hexamers on monomeric $A \beta 40(\mathrm{~mA} \beta 40)$ prepared using the same protocol as for $\mathrm{mA} \beta 42$ (Figure 7). No increase in slope gradient at early time points ( $0-1$ hour) was seen for $\mathrm{mA} \beta 40$ seeded with $5 \%$ and $10 \% \mathrm{C} 42$ or C99-derived $\mathrm{A} \beta 42$ hexamers respectively. The lack of nucleating effects at early stages of self-assembly was further consolidated by western blotting (Figure 7C) which revealed assembly sizes ranging from monomers to tetramers only for all conditions at T0 and 2 hours and no increase in higher molecular weight species. The ThT fluorescence for both 5 and 10\% C42-derived hexamer seeding does begin to slightly increase after 4 hours which could be indicative of a reduced ability of these hexamers to nucleate $A \beta 40$ compared to A 342 . A similar and more pronounced trend of increased ThT fluorescence is seen with 5 and $10 \%$ C99-derived $A \beta$ hexamers from 2 hours onwards. Interestingly, as the increase in fluorescence was not seen in $\mathrm{mA} \beta 42$ seeded with $10 \%$ C42-derived hexamers (Figure 6) and as we have shown the C99derived hexamers to disassemble into monomers, this data suggests some effect of two monomeric $A \beta$ isoforms interacting.

Together, we conclude that the cell-derived $\mathrm{A} \beta 42$ hexamers have a reduced nucleating propensity on $A \beta 40$ which further reiterates the direct link of hexamers as critical nuclei for $A \beta 42$ self-assembly. To be sure of this reduced capacity as opposed to inability, we seeded mA 340 with $30 \%$ C42 and C99derived hexamers (Supplemental Figure S6), which confirms that with enough hexamer, seeding can occur.

Our data demonstrate for the first time, the ability of cell-derived $A \beta 42$ hexamers to nucleate selfassembly with preferential nucleation of monomeric $A \beta 42$ compared to $A \beta 40$.

\section{$\underline{\text { Discussion }}$}

The process of self-assembly and its importance in $A \beta$ toxicity has been the focus of several research studies. The formation of intermediary oligomeric species during this process has been identified as being a determinant of cytotoxicity and we therefore investigated an $A \beta$ assembly that is responsible for facilitating nucleation dependent amyloid formation. To the best of our knowledge, we are the first 
group to present a thorough characterisation of cell-derived hexameric $\mathrm{A} \beta$ and provide more physiologically relevant evidence than in vitro studies using synthetic or recombinant peptides to further support this assembly to be a nucleation enhancing entity.

The identification of specific $A \beta$ intermediate assemblies that serve as nuclei for fibril formation has remained elusive due to their transient and heterogenous nature. Despite this, several studies have optimised the use of highly sensitive techniques such as small angle neutron scattering (SANS), small angle $\mathrm{x}$-ray scattering (SAX) and sedimentation velocity (SV) analysis complementary to SDS-PAGE of photo-induced cross linking of unmodified proteins (PICUP) solutions of $A \beta$ to detect hexameric assemblies involved in the early stages of self-assembly[26-28]. Furthermore, a recent native ion mobility-mass spectrometry study has also identified the formation of hexameric $A \beta$ and suggests a $\beta$ barrel structure in membrane mimicking environments[48]. In line with our data, these studies have all consistently observed the formation of hexameric $A \beta$ to be highly prone to the $A \beta 42$ sequence. However, these studies have relied heavily on synthetic peptides which cannot mimic a cellular environment. Here, in our experimental conditions, we have identified a non-self-assembling A $\beta 42$ specific hexamer that is present in both the cell lysates and media of transfected CHO cells.

$\mathrm{CHO}$ cells transfected with either $\mathrm{C} 99$ or $\mathrm{C} 42$ sequences showed the ability to form an A $\beta$ assembly that was $\sim 28 \mathrm{kDa}$ in size by western blotting, which is the theoretical size of an $\mathrm{A} \beta 42$ hexamer. FAD $\mathrm{A} \beta$ mutations in the $\mathrm{C} 99$ sequence also showed the formation of hexameric $\mathrm{A} \beta$ in the cell lysates and media of the $\mathrm{CHO}$ cells suggesting that the formation of this assembly is common in $\mathrm{A} \beta$ enriched and FAD related conditions. The commonality of hexameric $A \beta$ across these conditions highlights for the first time in a more physiological context, the importance of this assembly in conditions where $\mathrm{A} \beta$ selfassembly is accelerated.

Dot blotting following the isolation of these hexamers from the media of C42 and C99 transfected cells, confirmed them to be A 442 assemblies (Figure $2 B$ ). On the contrary, the monomeric A $\beta$ identified and isolated from the media of $\mathrm{C} 99$ transfected $\mathrm{CHO}$ cells was confirmed to be composed of the A $\beta 40$ sequence only. Furthermore, this monomer did not assemble into hexamers or any other higher molecular weight assemblies in the parameters of our experiments. This information is important as it confirms that the ability to readily form a hexameric assembly in a cellular context is an inherent property of the $A \beta 42$ primary sequence. This was further supported by the lack of a hexameric assembly seen in the cell lysates and media of $\mathrm{CHO}$ cells transfected with the $\mathrm{vC} 42$ sequence which has both F19S and G37D substitutions. These substitutions have been shown to negatively affect self-assembly propensity[35,49-55]. In this way, $\mathrm{vC} 42$ also begins to provide some evidence to suggest that both the F19 and G37 amino acids are important residues in the formation of a hexameric assembly. Interestingly, whilst this peptide was shown to remain largely monomeric for 7 days in vitro[44] we show here in cellular context, the formation of dimers within 48 hours. This further highlights the physiological relevance of our study in which we show the importance of translation of the protein, the cellular environment and the subsequent $\mathrm{A} \beta 42$ assemblies formed. 
Our data strongly supports the conclusion that the $A \beta$ hexamers we have identified are $A \beta 42$ specific assemblies (Figure 2B). This, combined with the assumption that there are no other isoforms present in the $\mathrm{C} 42$ condition, as well as $\mathrm{C} 99$-derived hexameric $\mathrm{A} \beta$ disassembling back into monomers over time (Figure 5C), suggests the initial nascent $A \beta 42$ monomer may be responsible for the formation of the A $\beta 42$ hexameric structures identified here. A previous study exploring the decapeptide $A \beta$ (21-30) showed its protease resistance was identical to full length of A 42 and likely to organise intramolecular monomer folding and therefore an initial folding nucleus[56]. This has been attributed to a $\beta$-turn formed and stabilised by both hydrophobic and electrostatic interactions between V24-K28 and K28E22/D23. FAD related mutations at positions G22 or D23 therefore disrupt this turn stability and have been shown to enhance subsequent assembly and oligomerisation[54,57,58]. The level of turn disruption correlates directly with enhanced oligomerisation for each mutation; from our results, the D23N mutation significantly disrupts the turn stability and enhances the formation of hexameric A $\beta 42$. The importance of this monomer folding nucleus in the formation of higher molecular weight assemblies, such as the hexamer, has been explained by the formation of the stabilised turn being a kinetically favoured folding event capable of facilitating the interaction between the central hydrophobic cluster (L17-A21) and the C-terminus, which is far more pronounced in A $\beta 42$ than in $\mathrm{A} \beta 40$ [58]. Together, this provides a plausible explanation as to 1) how the hexameric assembly is linked to folding events in the monomeric A $\beta 42$ peptide 2) why FAD mutations explored in this study do not negatively affect hexamer formation[59]. The disruption of the stabilising interactions in the decapeptide region of monomeric $\mathrm{A} \beta$ may occur in a physiological environment such an acidic $\mathrm{pH}$ (e.g. endosomes) where $A \beta$ assembly is known to be enhanced.

We also show that hexameric assemblies that are formed from $\mathrm{A} \beta$ after $\mathrm{C} 99$ processing are less stable than those formed from $\mathrm{C} 42$ where there is no upstream processing, suggesting processing may have an effect on structural properties. Despite this, both hexamers display nucleating properties which points to size being an important contributor for nucleating potential. Interestingly, hexamers have also been identified as being important intermediates in the self-assembly of $\beta 2$-microglobulin which suggests this assembly size may play an important role in the aggregation of several amyloid forming proteins[60].

The lack of self-assembly into higher molecular weight assemblies (Figure 5) over 7 days suggests that the hexamer we have identified may be an 'off-pathway' oligomer. However, several oligomeric species that are multimers of a hexameric unit e.g. ADDLs and $\mathrm{A} \beta * 56$ which would likely require hexameric self-association have been identified. It is beyond the scope of this study to firmly identify the A $\beta$ hexamer presented here as an off-pathway oligomer, however, in the parameters of our experiments this may be the case. Hexamers with the ability to self-associate may be in a different conformation and/or require suitable conditions for self-association such as membrane interactions or an acidic environment. Furthermore, the lack of association of two hexamers to form a dodecamer, which is thought to occur 
due to stacking of two hexamers with their hydrophobic C-terminal ends at the centre of the structure[22] was also observed by Osterlund and colleagues. They concluded the reduced entropic drive towards hexamer dimerisation is likely due to the $\mathrm{C}$-termini being stabilised in their experimental conditions which are likely mimicking the effects that would be seen in a lipid bilayer [48]. Therefore, perhaps the hexamers we isolate here are or have been associated to these lipid bilayers which affects their self-association properties.

Importantly, we show for the first time the nucleating potential of both $\mathrm{C} 42$ and C99 cell-derived hexamers and show this to be preferential to $\mathrm{mA} \beta 42$ over $\mathrm{mA} \beta 40$. This nucleation propensity is heavily reliant on the available monomers in solution, in line with the definition of a nucleus for self-assembly during the lag phase of amyloid formation[21]. We believe that as the hexamer is not a fibrillar species, it is likely directly involved in primary nucleation especially due to kinetics of assembly increasing at the very early time points of assembly when secondary nucleation, where newly formed fibrils provide the surface to catalyse new aggregates from the available monomers, is likely not yet occurring. The switch to secondary nucleation could occur as early as 2 hours as this is when we see the formation of fibrils in the well of the gels by western blotting. Secondary nucleation is dependent on both the concentration of monomers and existing fibrils, and as the gradient of the slope suggests slower aggregation of $\mathrm{mA} \beta 42$ seeded with $10 \% \mathrm{C} 42$ hexamer compared to $5 \%$ between $0-1 \mathrm{hr}$, perhaps there are more available monomers for secondary nucleation to occur in the later stages of self-assembly leading to more fibril formation and therefore higher ThT fluorescence[34]. However, to make solid conclusions regarding the microscopic steps involved in the self-assembly process, further in-depth work is required.

Overall, we demonstrate for the first time in a cellular context, the formation of hexameric A $\beta 42$ as a common feature in conditions where $A \beta 42$ self-assembly is accelerated and we have characterised these hexamers to be non-self-assembling entities that preferentially nucleate the aggregation of monomeric A 342 . Understanding mechanisms that can enhance or facilitate self-assembly in this way will ultimately aid our understanding of amyloid pathology.

\section{Materials and Methods}

\section{Chemicals and reagents}

Nitrocellulose membranes were purchased from GE Healthcare (Little Chalfont, UK) and Western Lightning ${ }^{\circledR}$ Plus-ECL from PerkinElmer (Waltham, MA, USA). The anti-A $\beta$ W0-2 (MABN10) primary antibody was from Abcam (Cambridge, UK), anti-A $\beta 40$ and anti-A $\beta 42$ primary antibodies were purchased from Merck Millipore (Darmstadt, Germany). The anti-C-ter primary antibody and horse radish peroxidase (HRP)-conjugated secondary antibodies were purchased from Sigma-Aldrich ( $\mathrm{St}$ Louis, MO, USA). TRIzol ${ }^{\mathrm{TM}}$ reagent and Complete ${ }^{\mathrm{TM}}$ protease inhibitor cocktail were from Roche 
(Basel, Switzerland). The cDNA synthesis kit and iQ SYBR Green Supermix were from Bio-Rad (Hercules, CA, USA).

\section{DNA constructs}

The pSVK3 empty plasmid (EP) as well as the -C40, -C42 and -C99 vectors including the fused signal peptide of APP were described previously [43,61]. QuickChange ${ }^{\circledR}$ site-specific mutagenesis (Stratagene, La Jolla, CA, USA) was used to produce the FAD mutants in the pSVK3-C99 template DNA, as previously described [62]. Primer sequences can be found in Supplemental Table S2.

\section{Cell Culture and Transfection}

Chinese hamster ovary (CHO) cell lines were cultured in Ham's F-12 medium supplemented with 10\% of FBS and 1\% Penicillin-Streptomycin (Life Technologies, Carlsbad, CA, USA). All cell cultures were maintained at $37^{\circ} \mathrm{C}$ in a humidified atmosphere $\left(5 \% \mathrm{CO}_{2}\right)$. Cells were passed every 4 days at $\sim 80 \%$ confluency and no longer used after passage 20.

For transfections with $\mathrm{C} 99$ and $\mathrm{A} \beta$ sequences, approximately $2.2 \times 10^{6} \mathrm{CHO}$ cells were plated 24 hours in advance in $10 \mathrm{~cm}$ petri dishes. A transfection mix of $15 \mu \mathrm{g}$ of DNA, 30 $\mu 1$ Lipo2000 ${ }^{\circledR}$ (Invitrogen) in $1 \mathrm{ml}$ Opti-MEM ${ }^{\circledR}$ was incubated for $15 \mathrm{mins}$ at room temperature before being added to cells. A $0 \%$ FBS medium change was carried out 24 hours after transfection and both cells and media were harvested after 48 hours of initial transfection.

\section{Western and dot Blotting}

After transfection, cell lysates were harvested and sonicated in lysis buffer (Tris $125 \mathrm{mM} \mathrm{pH} \mathrm{6.8,} \mathrm{4 \%}$ sodium dodecyl sulfate, $20 \%$ glycerol) with Complete $^{\mathrm{TM}}$ protease inhibitor cocktail. Media were centrifuged at $1200 \mathrm{~g}$ for $5 \mathrm{mins}$ to pellet any debris and dead cells and the supernatants were lyophilised by SpeedVac ${ }^{\mathrm{TM}}$. For cell lysates, $40 \mu \mathrm{g}$ of protein were heated for $10 \mathrm{mins}$ at $70^{\circ} \mathrm{C}$ in loading buffer (lysis buffer supplemented with 50mM DTT and LDS sample buffer). The lyophilised media were resuspended in $400 \mu 1$ milli-Q (mQ) water and the maximum sample volume was loaded. Samples were loaded and separated on 4-12\% NuPAGETM bis-tris gels (Life Technologies), and then transferred for 2 hours at $30 \mathrm{~V}$ onto $0.1 \mu \mathrm{m}$ nitrocellulose membranes. After $30 \mathrm{mins}$ of blocking ( $5 \%$ non-fat milk in $0.1 \%$ PBS-Tween), membranes were incubated at $4^{\circ} \mathrm{C}$ overnight with primary antibodies. Membranes were then washed three times in $0.1 \%$ PBS-Tween for 10 mins and incubated with horse radish peroxidase (HRP)-conjugated secondary antibodies for $1 \mathrm{hr}$ at room temperature. Finally, membranes were again washed three times for 10mins in PBS-Tween prior to ECL detection. Primary antibodies dilutions for western blotting are as follows: anti-A $\beta$ W0-2 (1:1.500) and anti-C-ter (1:2.000). Secondary antibodies dilutions are as follows: anti-mouse (1:10.000) or anti-rabbit (1:10.000). Both primary and secondary antibodies were diluted in $0.1 \%$ PBS-Tween. 
For dot blotting, $5 \mu 1$ of sample $(150 \mu \mathrm{M}$ isolated $\mathrm{A} \beta$ hexamers, $50 \mu \mathrm{M}$ synthetic monomeric $\mathrm{A} \beta)$ were spotted onto $0.1 \mu \mathrm{m}$ nitrocellulose membranes. Once the samples were dry, a further $5 \mu 1$ of sample were spotted twice on top and dried. The membranes were boiled in PBS for 3mins twice and blocked in 5\% non-fat milk in PBS-Tween for 30mins. After this the membranes were washed, incubated with antibodies and detected with ECL as described above. Primary antibodies dilutions for dot blotting are as follows: anti-A $\beta$ W0-2 (1:1.500), anti-A $\beta 40$ (1:1.000), anti-A $\beta 42$ (1:1.000). Secondary antibodies dilutions are as follows: anti-mouse (1:10.000) or anti-rabbit (1:10.000). Both primary and secondary antibodies were diluted in $0.1 \%$ PBS-Tween.

\section{Isolation of A $\beta$ assemblies: Gel Eluted Liquid Fraction Entrapment Electrophoresis (GELFrEE)}

6.6x $10^{6} \mathrm{CHO}$ cells were seeded in $\mathrm{T} 175$ flasks 24 hours before transfection. Cells were transfected with $45 \mu \mathrm{g}$ of DNA using Lipofectamine ${ }^{\circledR} 2000$ and a $0 \%$ FBS medium change was carried out 24 hours after transfection. The media were harvested and lyophilised 48hours after initial transfection and resuspended in $1 \mathrm{ml}$ milli-Q water. $\mathrm{A} \beta$ was immunoprecipitated using Sepharose A beads (Invitrogen) coated with the anti-A $\beta$ W0-2 antibody. For immunoprecipitation, $100 \mu 1$ recombinant Sepharose A beads $(50 \mathrm{mg} / \mathrm{ml})$ were incubated with the medium for 3hours as a pre-clearing step. This was then centrifuged at $>15.000 \mathrm{~g}$ for 5 mins and the beads were discarded. The supernatant was next incubated with $5 \mu 1$ W0-2 antibody for $1 \mathrm{hr}$ at $4^{\circ} \mathrm{C}$, after which $100 \mu \mathrm{l}$ fresh Sepharose beads were added and incubated at $4{ }^{\circ} \mathrm{C}$ overnight. The beads were then washed 3 times with $\mathrm{mQ}$ water and resuspended in $104 \mu \mathrm{mQ}$ water, $16 \mu \mathrm{l}$ of DTT $0.5 \mathrm{M}$ and $30 \mu 1$ Tris-Acetate loading buffer. The mixture was boiled at $95^{\circ} \mathrm{C}$ for $10 \mathrm{mins}$ and centrifuged at $>15.000 \mathrm{~g}$ for $5 \mathrm{mins}$. The supernatant was loaded into the GELFrEE $^{\circledR} 8100$ system and run using the following method; Step 1- 16 mins at 50V, Step 2- 40mins at 50V (Monomer fraction), Step 3-4mins at 50V, Step 4- 6 mins at 70V, Step 4- 13mins at 85V and Step 6- 38mins at 85V (Hexamer Fraction).

Samples were collected in the system running buffer (1X buffer; 1\% HEPES, 0.01\% EDTA, 0.1\% SDS and $0.1 \%$ Tris) and kept on ice. The monomeric fraction was then put through a buffer equilibrated $7 \mathrm{~K}$ MWCO Zeba buffer-exchange column (Thermo Scientific) to remove the Tris-Acetate blue sample buffer. The absorbance at $280 \mathrm{~nm}$ was read using a BioPhotometer ${ }^{\circledR}$ D30 (Eppendorf) and the concentration of the collected $A \beta$ assemblies were calculated using the molecular coefficient of 1490 M-1cm-1; (A280/1490) x1000 x 1000.

For assembly over time experiments, monomeric and hexameric samples were incubated at room temperature and $20 \mu 1$ aliquots were taken for western blotting at each time point.

\section{ECLIA}

Quantification of $A \beta_{38}, A \beta_{40}$, and $A \beta_{42}$ monomeric peptides in the serum free media of $C 99$ transfected $\mathrm{CHO}$ cells was achieved using the $\mathrm{A} \beta$ multiplex electro-chemiluminescence immunoassay (ECLIA; 
Meso Scale Discovery, Gaithersburg, MD, USA) as previously described [63]. A $\beta$ were quantified with the human $\mathrm{A} \beta$ specific $6 \mathrm{E} 10$ multiplex assay according to the manufacturer's instructions.

\section{Synthetic monomeric Aß preparation and seeding}

Monomeric solutions of $A \beta$ were prepared as previously described $[44,46]$. Briefly, recombinant $A \beta 40$ and $\mathrm{A} \beta 42$ were purchased from rPeptide as 1,1,1,3,3,3-Hexafluoro-2-propanol (HFIP) films. 0.2mg aliquots of peptide were solubilised in $200 \mu 1$ HFIP (Sigma-Aldrich) to disaggregate any preformed aggregates. The solution was then vortexed for $1 \mathrm{~min}$ and sonicated in a water bath for $5 \mathrm{mins}$. The HFIP was then dried off using a steady flow of nitrogen gas. $200 \mu 1$ of anhydrous dimethyl sulfoxide (DMSO) (Sigma-Aldrich) was then added and the solution was vortexed for $1 \mathrm{~min}$. The solution was then put through a buffer equilibrated 7K MWCO Zeba buffer-exchange column (Thermo Scientific) at $4{ }^{\circ} \mathrm{C}$. The protein solution was then kept on ice whilst the absorbance at $280 \mathrm{~nm}$ was measured using a BioPhotometer ${ }^{\circledR}$ D30 (Eppendorf) spectrophotometer. The concentration was calculated using the molecular coefficient of $1490 \mathrm{M}-1 \mathrm{~cm}-1$; (A280/1490) x1000 x 1000. Solutions were immediately diluted to $50 \mu \mathrm{M}$ in buffer and this was taken to be the new working stock.

\section{ThT Assay}

To assess the self-assembly of the isolated hexameric $A \beta$, the fluorescence of $20 \mu \mathrm{M}$ ThT (SigmaAldrich) in $150 \mu \mathrm{M}$ isolated hexamer was measured over 48 hours in 96 well plates using the VICTOR ${ }^{\circledR}$ Multilabel Plate Reader (PerkinElmer, Waltham, MA, USA). For seeding experiments, fluorescence of $20 \mu \mathrm{M}$ ThT in $50 \mu \mathrm{M}$ monomeric $\mathrm{A} \beta 40$ or A $\beta 42$ was monitored over 24hours. Fluorescence readings were obtained at room temperature with excitation and emission wavelengths set at $460 \mathrm{~nm}$ and $483 \mathrm{~nm}$ respectively.

\section{Mass Spectrometry}

The fractions of the cellular samples from the GELFrEE ${ }^{\circledR}$ system were passed through HiPPR ${ }^{\mathrm{TM}}$ Detergent Removal $0.1 \mathrm{ml}$ columns (ThermoFisher Scientific), previously equilibrated with a $25 \mathrm{mM}$ ammonium bicarbonate $\left(\mathrm{NH}_{4} \mathrm{HCO}_{3}\right)$ solution, to remove the detergent from the solution. The samples were centrifuged for $2 \mathrm{mins}$ at $1500 \mathrm{~g}$, then lyophilized.

Samples were then resuspended in $50 \mathrm{mM}$ ammonium bicarbonate before being first reduced $(10 \mathrm{mM}$ dithiothreitol) for $40 \mathrm{mins}$ at $56^{\circ} \mathrm{C}$, alkylated $(20 \mathrm{mM}$ iodoacetamide) for $30 \mathrm{mins}$ at room temperature, and finally digested with trypsin for 16 hours at $37^{\circ} \mathrm{C}(1 / 50 \mathrm{w} / \mathrm{w}$ enzyme/proteins ratio). Reactions were stopped by acidifying the solution using 10\% TFA. Generated peptides were then analyzed by LCMS/MS.

Peptides were separated by reversed-phase chromatography using Ultra Performance Liquid Chromatography (UPLC-MClass, HSS T3 column, Waters, Milford, MA, USA) in one dimension with 
a linear gradient of acetonitrile ( 5 to $40 \%$ in $70 \mathrm{mins}$, solvent A was water $0.1 \%$ formic acid, solvent B was acetonitrile $0.1 \%$ formic acid) at a $600 \mathrm{nl} / \mathrm{min}$ flow rate. The chromatography system was coupled with a Thermo Scientific Q Exactive ${ }^{\mathrm{TM}}$ Plus hybrid quadrupole-Orbitrap ${ }^{\mathrm{TM}}$ mass spectrometer (ThermoFisher Scientific, Waltham, MA, USA), with a targeted method. The targeted masses are the $\mathrm{m} / \mathrm{z}$ of the three following doubly charged peptides, that result from the trypsin digestion: LVFFAEDVGSNK m/z 663.3404, GAIIGLMVGGVV m/z 543.3230 and GAIIGLMVGGVVIA m/z 635.3836.

Full-MS scans were acquired at 70.000 mass resolving power (full width at half maximum). A mass range from 400 to $1750 \mathrm{~m} / \mathrm{z}$ was acquired in MS mode, and $3 \times 10^{6}$ ions were accumulated. Ion trap Higher energy Collision Dissociation fragmentations at NCE (Normalized Collision Energy) 25 were performed within 2amu isolation windows.

Raw MS files were analyzed by Proteome Discoverer 2.1.1.21 software (Thermo Scientific). MS/MS spectra were compared to the Uniprot Cricetulus griseus protein database, in which had been added the sequence of two main human amyloid peptides $A \beta 40$ and $A \beta 42$. Due to this restricted length in amino acids, the criteria for identification of each protein has been set up to one unique peptide per protein. The false discovery rate (FDR) was set to 0.01 on both protein and peptide levels. The tolerance on mass accuracy was set at $5 \mathrm{ppm}$ (10 ppm for MS/MS).

\section{qPCR}

RNAs were extracted from cells in TRIPure ${ }^{\circledR}$ reagent and reverse-transcribed using an iScript cDNA synthesis kit. qPCR conditions were $95^{\circ} \mathrm{C}$ for 30 secs, followed by 40 cycles of 30 secs at $95^{\circ} \mathrm{C}, 45 \mathrm{secs}$ at $60^{\circ} \mathrm{C}$ and $15 \mathrm{secs}$ at $79^{\circ} \mathrm{C}$ and ended by 1 cycle of $15 \mathrm{secs}$ at $79^{\circ} \mathrm{C}$ and $30 \mathrm{secs}$ at $60^{\circ} \mathrm{C}$. The relative changes in the target gene-to-GAPDH mRNA ratio were determined by the $2^{(-\Delta \Delta \mathrm{Ct})}$ calculation. The sequences for qPCR primers are provided in Supplemental Table S3.

\section{Data Availability}

The datasets generated during and/or analysed during the current study are available from the corresponding author on reasonable request. 


\section{References}

1. Selkoe, D. J. \& Hardy, J. The amyloid hypothesis of Alzheimer's disease at 25 years. EMBO Mol Med 8, 595-608, doi:10.15252/emmm.201606210 (2016).

2. Takami, M. et al. gamma-Secretase: successive tripeptide and tetrapeptide release from the transmembrane domain of beta-carboxyl terminal fragment. J Neurosci 29, 13042-13052, doi:10.1523/JNEUROSCI.2362-09.2009 (2009).

3. Qi-Takahara, Y. et al. Longer forms of amyloid beta protein: implications for the mechanism of intramembrane cleavage by gamma-secretase. J Neurosci 25, 436-445, doi:10.1523/JNEUROSCI.1575-04.2005 (2005).

4. Bolduc, D. M., Montagna, D. R., Seghers, M. C., Wolfe, M. S. \& Selkoe, D. J. The amyloid-beta forming tripeptide cleavage mechanism of gamma-secretase. Elife 5, doi:10.7554/eLife.17578 (2016).

5. Serpell, L. C. Alzheimer's amyloid fibrils: structure and assembly. Biochim Biophys Acta 1502, 16-30, doi:10.1016/s0925-4439(00)00029-6 (2000).

6. Selkoe, D. J. Alzheimer's disease: a central role for amyloid. J Neuropathol Exp Neurol 53, 438447, doi:10.1097/00005072-199409000-00003 (1994).

7. Benilova, I., Karran, E. \& De Strooper, B. The toxic Abeta oligomer and Alzheimer's disease: an emperor in need of clothes. Nat Neurosci 15, 349-357, doi:10.1038/nn.3028 (2012).

8. McLean, C. A. et al. Soluble pool of Abeta amyloid as a determinant of severity of neurodegeneration in Alzheimer's disease. Ann Neurol 46, 860-866, doi:10.1002/15318249(199912)46:6<860::aid-ana8>3.0.co;2-m (1999).

9. Jongbloed, W. et al. Amyloid-beta oligomers relate to cognitive decline in Alzheimer's disease. J Alzheimers Dis 45, 35-43, doi:10.3233/JAD-142136 (2015).

10. Amar, F. et al. The amyloid-beta oligomer Abeta*56 induces specific alterations in neuronal signaling that lead to tau phosphorylation and aggregation. Sci Signal 10, doi:10.1126/scisignal.aal2021 (2017).

11. Lesne, S. E. et al. Brain amyloid-beta oligomers in ageing and Alzheimer's disease. Brain 136, 1383-1398, doi:10.1093/brain/awt062 (2013).

12. Ladiwala, A. R. et al. Conformational differences between two amyloid beta oligomers of similar size and dissimilar toxicity. J Biol Chem 287, 24765-24773, doi:10.1074/jbc.M111.329763 (2012).

13. Broersen, K., Rousseau, F. \& Schymkowitz, J. The culprit behind amyloid beta peptide related neurotoxicity in Alzheimer's disease: oligomer size or conformation? Alzheimers Res Ther $\mathbf{2}$, 12, doi:10.1186/alzrt36 (2010).

14. Deshpande, A., Mina, E., Glabe, C. \& Busciglio, J. Different conformations of amyloid beta induce neurotoxicity by distinct mechanisms in human cortical neurons. J Neurosci 26, 60116018, doi:10.1523/JNEUROSCI.1189-06.2006 (2006).

15. Lambert, M. P. et al. Diffusible, nonfibrillar ligands derived from Abeta1-42 are potent central nervous system neurotoxins. Proc Natl Acad Sci U S A 95, 6448-6453, doi:10.1073/pnas.95.11.6448 (1998).

16. Townsend, M., Shankar, G. M., Mehta, T., Walsh, D. M. \& Selkoe, D. J. Effects of secreted oligomers of amyloid beta-protein on hippocampal synaptic plasticity: a potent role for trimers. J Physio/ 572, 477-492, doi:10.1113/jphysiol.2005.103754 (2006).

17. Shankar, G. M. et al. Natural oligomers of the Alzheimer amyloid-beta protein induce reversible synapse loss by modulating an NMDA-type glutamate receptor-dependent signaling pathway. J Neurosci 27, 2866-2875, doi:10.1523/JNEUROSCI.4970-06.2007 (2007).

18. Shankar, G. M. et al. Amyloid-beta protein dimers isolated directly from Alzheimer's brains impair synaptic plasticity and memory. Nat Med 14, 837-842, doi:10.1038/nm1782 (2008).

19. Ferrone, F. Analysis of protein aggregation kinetics. Methods Enzymol 309, 256-274, doi:10.1016/s0076-6879(99)09019-9 (1999). 
20. Roychaudhuri, R., Yang, M., Hoshi, M. M. \& Teplow, D. B. Amyloid beta-protein assembly and Alzheimer disease. J Biol Chem 284, 4749-4753, doi:10.1074/jbc.R800036200 (2009).

21. Scheidt, T. et al. Secondary nucleation and elongation occur at different sites on Alzheimer's amyloid-beta aggregates. Sci Adv 5, eaau3112, doi:10.1126/sciadv.aau3112 (2019).

22. Bernstein, S. L. et al. Amyloid-beta protein oligomerization and the importance of tetramers and dodecamers in the aetiology of Alzheimer's disease. Nat Chem 1, 326-331, doi:10.1038/nchem.247 (2009).

23. Bitan, G. et al. Amyloid beta -protein (Abeta) assembly: Abeta 40 and Abeta 42 oligomerize through distinct pathways. Proc Natl Acad Sci U S A 100, 330-335, doi:10.1073/pnas.222681699 (2003).

24. Cernescu, M. et al. Laser-induced liquid bead ion desorption mass spectrometry: an approach to precisely monitor the oligomerization of the beta-amyloid peptide. Anal Chem 84, 52765284, doi:10.1021/ac300258m (2012).

25. Ono, K., Condron, M. M. \& Teplow, D. B. Structure-neurotoxicity relationships of amyloid betaprotein oligomers. Proc Natl Acad Sci U S A 106, 14745-14750, doi:10.1073/pnas.0905127106 (2009).

26. Bitan, G., Lomakin, A. \& Teplow, D. B. Amyloid beta-protein oligomerization: prenucleation interactions revealed by photo-induced cross-linking of unmodified proteins. J Biol Chem 276, 35176-35184, doi:10.1074/jbc.M102223200 (2001).

27. Bitan, G. \& Teplow, D. B. Rapid photochemical cross-linking--a new tool for studies of metastable, amyloidogenic protein assemblies. Acc Chem Res 37, 357-364, doi:10.1021/ar000214l (2004).

28. Wolff, M. et al. Abeta42 pentamers/hexamers are the smallest detectable oligomers in solution. Sci Rep 7, 2493, doi:10.1038/s41598-017-02370-3 (2017).

29. Lesne, S. et al. A specific amyloid-beta protein assembly in the brain impairs memory. Nature 440, 352-357, doi:10.1038/nature04533 (2006).

30. Bolognesi, B. et al. Single point mutations induce a switch in the molecular mechanism of the aggregation of the Alzheimer's disease associated Abeta42 peptide. ACS Chem Biol 9, 378-382, doi:10.1021/cb400616y (2014).

31. Luheshi, L. M. et al. Systematic in vivo analysis of the intrinsic determinants of amyloid Beta pathogenicity. PLOS Biol 5, e290, doi:10.1371/journal.pbio.0050290 (2007).

32. Peralvarez-Marin, A. et al. Influence of residue 22 on the folding, aggregation profile, and toxicity of the Alzheimer's amyloid beta peptide. Biophys J 97, 277-285, doi:10.1016/j.bpj.2009.04.017 (2009).

33. Johansson, A. S. et al. Physiochemical characterization of the Alzheimer's disease-related peptides A beta 1-42Arctic and A beta 1-42wt. FEBS J 273, 2618-2630, doi:10.1111/j.17424658.2006.05263.x (2006).

34. Yang, X. et al. On the role of sidechain size and charge in the aggregation of Abeta42 with familial mutations. Proc Natl Acad Sci U S A 115, E5849-E5858, doi:10.1073/pnas.1803539115 (2018).

35. Ahmed, M. et al. Structural conversion of neurotoxic amyloid-beta(1-42) oligomers to fibrils. Nat Struct Mol Biol 17, 561-567, doi:10.1038/nsmb.1799 (2010).

36. Melchor, J. P., McVoy, L. \& Van Nostrand, W. E. Charge alterations of E22 enhance the pathogenic properties of the amyloid beta-protein. J Neurochem 74, 2209-2212, doi:10.1046/j.1471-4159.2000.0742209.x (2000).

37. Murakami, K. et al. Synthesis, aggregation, neurotoxicity, and secondary structure of various A beta 1-42 mutants of familial Alzheimer's disease at positions 21-23. Biochem Biophys Res Commun 294, 5-10, doi:10.1016/S0006-291X(02)00430-8 (2002).

38. Murakami, K. et al. Neurotoxicity and physicochemical properties of Abeta mutant peptides from cerebral amyloid angiopathy: implication for the pathogenesis of cerebral amyloid 
angiopathy and Alzheimer's disease. J Biol Chem 278, 46179-46187, doi:10.1074/jbc.M301874200 (2003).

39. Grabowski, T. J., Cho, H. S., Vonsattel, J. P., Rebeck, G. W. \& Greenberg, S. M. Novel amyloid precursor protein mutation in an lowa family with dementia and severe cerebral amyloid angiopathy. Ann Neurol 49, 697-705, doi:10.1002/ana.1009 (2001).

40. Hendriks, L. et al. Presenile dementia and cerebral haemorrhage linked to a mutation at codon 692 of the beta-amyloid precursor protein gene. Nat Genet 1, 218-221, doi:10.1038/ng0692218 (1992).

41. Miravalle, L. et al. Substitutions at codon 22 of Alzheimer's abeta peptide induce diverse conformational changes and apoptotic effects in human cerebral endothelial cells. J Biol Chem 275, 27110-27116, doi:10.1074/jbc.M003154200 (2000).

42. Nilsberth, C. et al. The 'Arctic' APP mutation (E693G) causes Alzheimer's disease by enhanced Abeta protofibril formation. Nat Neurosci 4, 887-893, doi:10.1038/nn0901-887 (2001).

43. Decock, M. et al. Glycines from the APP GXXXG/GXXXA Transmembrane Motifs Promote Formation of Pathogenic Abeta Oligomers in Cells. Front Aging Neurosci 8, 107, doi:10.3389/fnagi.2016.00107 (2016).

44. Marshall, K. E. et al. A critical role for the self-assembly of Amyloid-beta1-42 in neurodegeneration. Sci Rep 6, 30182, doi:10.1038/srep30182 (2016).

45. Jarrett, J. T., Berger, E. P. \& Lansbury, P. T., Jr. The carboxy terminus of the beta amyloid protein is critical for the seeding of amyloid formation: implications for the pathogenesis of Alzheimer's disease. Biochemistry 32, 4693-4697, doi:10.1021/bi00069a001 (1993).

46. Broersen, K. et al. A standardized and biocompatible preparation of aggregate-free amyloid beta peptide for biophysical and biological studies of Alzheimer's disease. Protein Eng Des Sel 24, 743-750, doi:10.1093/protein/gzr020 (2011).

47. Vadukul, D. M., Gbajumo, O., Marshall, K. E. \& Serpell, L. C. Amyloidogenicity and toxicity of the reverse and scrambled variants of amyloid-beta 1-42. FEBS Lett 591, 822-830, doi:10.1002/1873-3468.12590 (2017).

48. Osterlund, N., Moons, R., Ilag, L. L., Sobott, F. \& Graslund, A. Native Ion Mobility-Mass Spectrometry Reveals the Formation of beta-Barrel Shaped Amyloid-beta Hexamers in a Membrane-Mimicking Environment. J Am Chem Soc 141, 10440-10450, doi:10.1021/jacs.9b04596 (2019).

49. Cukalevski, R. et al. Role of aromatic side chains in amyloid beta-protein aggregation. ACS Chem Neurosci 3, 1008-1016, doi:10.1021/cn300073s (2012).

50. Esler, W. P. et al. Point substitution in the central hydrophobic cluster of a human betaamyloid congener disrupts peptide folding and abolishes plaque competence. Biochemistry 35, 13914-13921, doi:10.1021/bi961302+ (1996).

51. Hilbich, C., Kisters-Woike, B., Reed, J., Masters, C. L. \& Beyreuther, K. Substitutions of hydrophobic amino acids reduce the amyloidogenicity of Alzheimer's disease beta A4 peptides. J Mol Biol 228, 460-473, doi:10.1016/0022-2836(92)90835-8 (1992).

52. Wurth, C., Guimard, N. K. \& Hecht, M. H. Mutations that reduce aggregation of the Alzheimer's Abeta42 peptide: an unbiased search for the sequence determinants of Abeta amyloidogenesis. J Mol Biol 319, 1279-1290, doi:10.1016/S0022-2836(02)00399-6 (2002).

53. Gazit, E. A possible role for pi-stacking in the self-assembly of amyloid fibrils. FASEB J 16, 7783, doi:10.1096/fj.01-0442hyp (2002).

54. Masuda, Y. et al. Verification of the turn at positions 22 and 23 of the beta-amyloid fibrils with Italian mutation using solid-state NMR. Bioorg Med Chem 13, 6803-6809, doi:10.1016/j.bmc.2005.07.071 (2005).

55. Murakami, K. et al. Formation and stabilization model of the 42-mer Abeta radical: implications for the long-lasting oxidative stress in Alzheimer's disease. J Am Chem Soc 127, 15168-15174, doi:10.1021/ja054041c (2005). 
56. Roychaudhuri, R., Yang, M., Condron, M. M. \& Teplow, D. B. Structural dynamics of the amyloid beta-protein monomer folding nucleus. Biochemistry 51, 3957-3959, doi:10.1021/bi300350p (2012).

57. Grant, M. A. et al. Familial Alzheimer's disease mutations alter the stability of the amyloid beta-protein monomer folding nucleus. Proc Natl Acad Sci U S A 104, 16522-16527, doi:10.1073/pnas.0705197104 (2007).

58. Lazo, N. D., Grant, M. A., Condron, M. C., Rigby, A. C. \& Teplow, D. B. On the nucleation of amyloid beta-protein monomer folding. Protein Sci 14, 1581-1596, doi:10.1110/ps.041292205 (2005).

59. Krone, M. G. et al. Effects of familial Alzheimer's disease mutations on the folding nucleation of the amyloid beta-protein. J Mol Biol 381, 221-228, doi:10.1016/j.jmb.2008.05.069 (2008).

60. Karamanos, T. K. et al. Structural mapping of oligomeric intermediates in an amyloid assembly pathway. Elife 8, doi:10.7554/eLife.46574 (2019).

61. Kienlen-Campard, P. et al. Amyloidogenic processing but not amyloid precursor protein (APP) intracellular C-terminal domain production requires a precisely oriented APP dimer assembled by transmembrane GXXXG motifs. J Biol Chem 283, 7733-7744, doi:10.1074/jbc.M707142200 (2008).

62. Ben Khalifa, N. et al. Structural features of the KPI domain control APP dimerization, trafficking, and processing. FASEB J 26, 855-867, doi:10.1096/fj.11-190207 (2012).

63. Hage, S. et al. Characterization of Pterocarpus erinaceus kino extract and its gamma-secretase inhibitory properties. J Ethnopharmacol 163, 192-202, doi:10.1016/j.jep.2015.01.028 (2015).

\section{Acknowledgments}

The authors thank Esther Paître and Pierre Burguet for their technical support. We also thank Loic Quinton for kindly providing us with the Gel Eluted Liquid Fraction Entrapment Electrophoresis (GELFrEE) 8100 system. Funding to P.K.C is acknowledged from SAO-FRA Alzheimer Research Foundation, Fondation Louvain and Queen Elisabeth Medical Research Foundation (FMRE to P.K.C and LQ). The work was supported by funds from FNRS grant PDRT.0177.18 to P.K.C and LQ.

\section{Author Contributions}

D.M.V designed and performed research, analysed data and wrote the manuscript. C.V performed research and analysed data. P.B performed mass spectrometry experiments under the supervision of L.Q. N.C and S.C analysed and interpreted data. L.C.S kindly provided us with the vA $\beta$ sequence and provided guidance with interpretation of data. P.K.C. supervised, designed research project and interpretations. All authors reviewed the manuscript.

\section{Additional Information}

The authors declare no competing interests. Correspondence and requests for materials should be addressed to P.K.C. 


\section{Figure Legends}

Figure 1. A $\beta$ profile in transfected CHO cells detected with the anti-A $\beta$ W0-2 antibody. (A) Hexamer formation (red box) is seen in cell lysates of $\mathrm{CHO}$ cells transfected with $\mathrm{C} 99$ (right panel). Monomers (M), Dimers (D), Trimers (T) and Hexamers (H), were detected in the culture media of C99 transfected CHO cells (left panel). (B, right panel) No assemblies were detected in the cell lysates of $\mathrm{C} 40$ transfected $\mathrm{CHO}$ cells, however, hexameric $\mathrm{A} \beta$ was detected in cell lysates of $\mathrm{C} 42$ transfected $\mathrm{CHO}$ cells. (B, left panel) Hexameric $\mathrm{A} \beta$ is also detected in culture media of $\mathrm{CHO}$ cells transfected with $\mathrm{C} 42$ only. (C) Hexameric A $\beta$ is detected in cell lysates and media of $\mathrm{CHO}$ cells transfected with FAD mutations in the C99 sequence. (D) Hexamer formation was quantified on the C99 signal (black arrow) for each of the mutations. The D23N (Iowa) mutation showed a significant increase in hexamer formation (**) compared to C99. One-way ANOVA with Tukey's post hoc comparison where $\mathrm{p}=<0.01(*),<0.001$ $(* *),<0(* * *)$. Error bars are expressed as $\pm \operatorname{SEM}(\mathrm{N}=3)$.

Figure 2. Isolation of $A \beta$ assemblies and identification of hexameric assembly $A \beta$ isoform. (A) $\mathrm{A} \beta$ was immunoprecipitated using the W0-2 antibody and separated by size using the GELFrEE $^{\circledR} 8100$ system. CHO cells transfected with the empty plasmid (EP) and immunoprecipitated for $\mathrm{A} \beta$ did not show isolated assemblies in any fraction. From C99 transfected $\mathrm{CHO}$ cells, we are able to isolate monomeric $\mathrm{A} \beta$ (orange box) in Fraction 1 and hexameric $A \beta$ (red box) in Fraction 5. Only hexameric $A \beta$ was isolated (Fraction 5) from $C 42$ transfected CHO cells. (B) Dot blotting was carried out to identify the hexameric $A \beta$ isoform using the W0-2, anti-A $\beta 40$ and anti-A $\beta 42$ antibodies. Synthetic $A \beta 40$ and $A \beta 42$ were used as positive controls. Both $\mathrm{C} 42$ and $\mathrm{C} 99$ derived $\mathrm{A} \beta$ hexamers are detected by the anti-A $\beta$ W0-2 antibody (left panel) and anti-A $\beta 42$ antibody (right panel), however, not by the anti-A $\beta 40$ antibody (middle panel) confirming the hexamers are composed of $\mathrm{A} \beta 42$.

Figure 3. Hexamer formation is directly related to Aß42 self-assembly propensity. $\mathrm{CHO}$ cells transfected with vC42 (F19S, G37D), did not form hexameric A $\beta$ in either the cell lysates or media detected by the W0-2 antibody. However, dimers (green box) were detected in the cell lysates of vC42 transfected $\mathrm{CHO}$ cells.

Figure 4. Hexamer formation is directly related to Aß42 primary sequence. (A) Isolated monomeric $A \beta$ incubated at room temperature over $48 \mathrm{hrs}$ does not assemble into hexameric or other higher molecular weight assemblies as assessed by western blotting detected with the W0-2 antibody. (B) ECLIA measurements $(\mathrm{N}=5)$ on the media of $\mathrm{C} 99$ transfected $\mathrm{CHO}$ cells 
identified $\mathrm{A} \beta 40$ as the most abundant monomeric $\mathrm{A} \beta$ isoform $(80.9 \mathrm{pg} / \mathrm{ml})$. Low concentrations of $\mathrm{A} \beta 38(24.7 \mathrm{pg} / \mathrm{ml})$ and even lower concentrations of $\mathrm{A} \beta 42(1.3 \mathrm{pg} / \mathrm{ml})$ were detected in this culture media (C) CLC-MS/MS identification of A $\beta 40$ in the C99 Sample. Top left panel: extracted ion chromatogram of the $[\mathrm{M}+2 \mathrm{H}] 2+$ detected at 62 minutes, for the standard (top) and the C99 sample (bottom). Top right Panel: mass spectra of the A $\beta 40$ fragment ion showing the isotopic pattern for the standard (top) and the C99 sample (bottom). Bottom panel: MS/MS annotated spectrum characterising an A $\beta 40$ fragment from the C99 sample.

Figure 5. Isolated hexameric Aß does not self-assemble into higher molecular weight assemblies (A) $150 \mu \mathrm{M}$ isolated hexameric $\mathrm{A} \beta$ from $\mathrm{C} 42$ and $\mathrm{C} 99$ transfected $\mathrm{CHO}$ cells was incubated with $20 \mu \mathrm{M}$ ThT and fluorescence was monitored over $48 \mathrm{hrs}$ as a measure of fibrillogenesis. No increase in fluorescence was seen for either of the isolated hexamers. (B and C) Western blotting and detection with the W0-2-antibody revealed both hexamers (red box) do not assemble into higher molecular weight assemblies over 7days. Hexamers from C99 transfected CHO cells, do, however disassemble into monomers (orange box) over time as was detected from $2 \mathrm{hrs}$ onwards.

Figure 6. Isolated $\mathrm{C} 42$ and $\mathrm{C} 99$ derived hexameric $\mathrm{A} \beta$ nucleate monomeric A $\beta 42$ (mAß42). (A) $50 \mu \mathrm{M} \mathrm{mA} 342$ was seeded with 5- or $10 \%$ hexamer and the solution was the incubated with $20 \mu \mathrm{M}$ ThT. Fluorescence was monitored over 24 hours. (B) Addition of both 5- and 10\% C42 hexamer results in an immediate increase in ThT fluorescence (0-2 hours). (C) Western blotting with the W0-2 antibody revealed all seeding conditions form higher molecular weight assemblies at T0 and by $2 \mathrm{hrs}$ fibrils are seen 'stuck' in the wells of the gel. (D) The gradient of the ThT fluorescence slope was calculated at the early time points of aggregation (0-1 hour) and One-way ANOVA with Tukey's post hoc comparison where $p=<0.01(*),<$ $0.001(* *),<0(* * *)$, revealed addition of $5 \% \mathrm{C} 42$ hexamer significantly $(* *)$ increased the kinetics of aggregation compared to mA 342 only as did the addition of 5\% C99 derived hexamer (*). Error bars are expressed as \pm SEM.

Figure 7. Isolated C42 and C99 derived hexameric Aß do not readily nucleate monomeric A $\beta 40$ (mAß40). (A) $50 \mu \mathrm{M}$ mA $\beta 40$ was seeded with 5- or $10 \%$ hexamer and the solution was then incubated with $20 \mu \mathrm{M}$ ThT. Fluorescence was monitored over 4 hours. (B) Addition of both 5 - and 10\% did not result in an increased fluorescence at early time points (0-2 hourss) (C) Western blotting detected with the W0-2 antibody revealed seeding conditions with both 
hexamers does not lead to the formation of higher molecular weight assemblies compared to mAß40 only. 


\section{Figures}
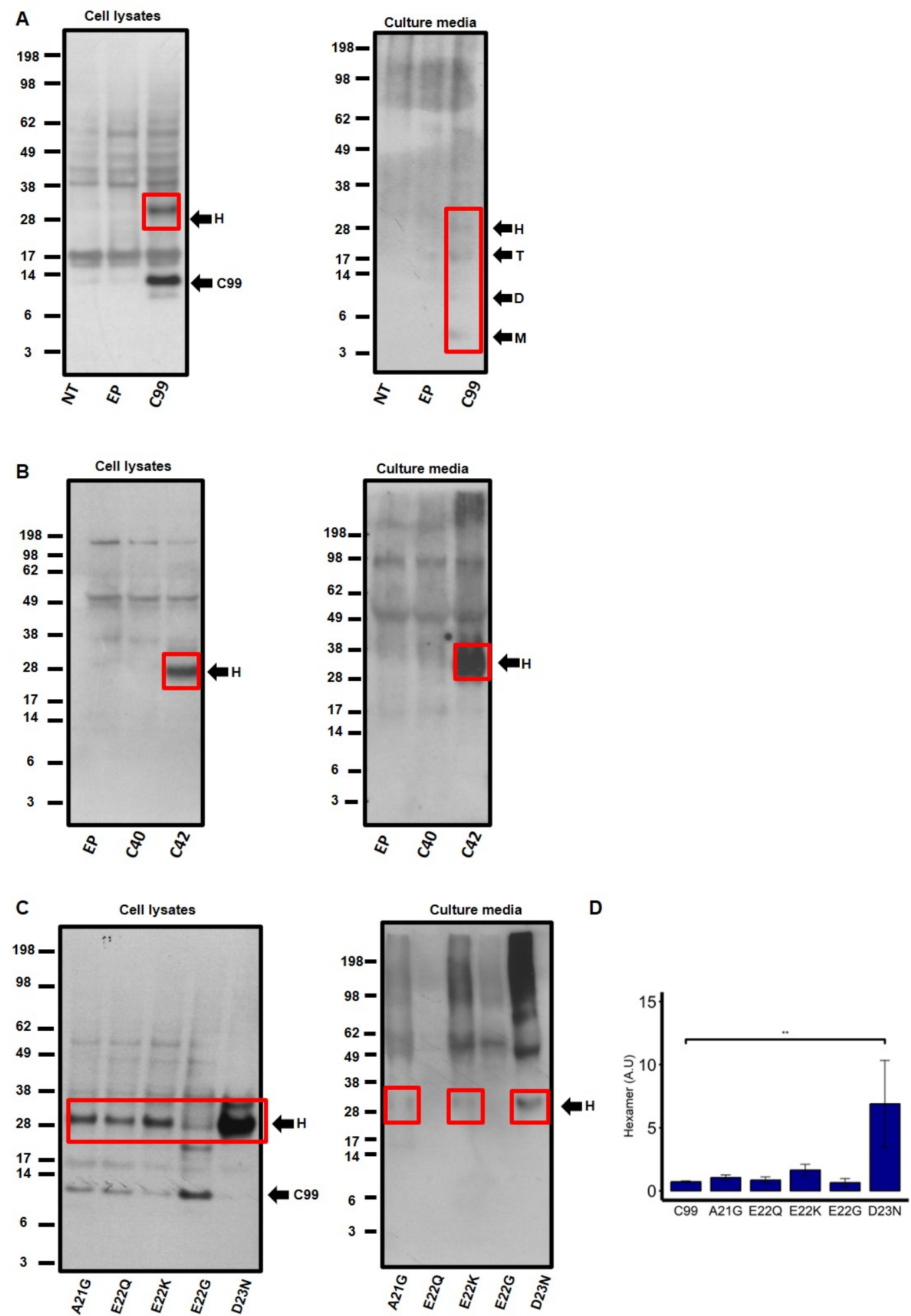

Figure 1. A $\beta$ profile in transfected $\mathrm{CHO}$ cells detected with the anti-A $\beta$ W0-2 antibody. 
A

ERACTIONS

C99

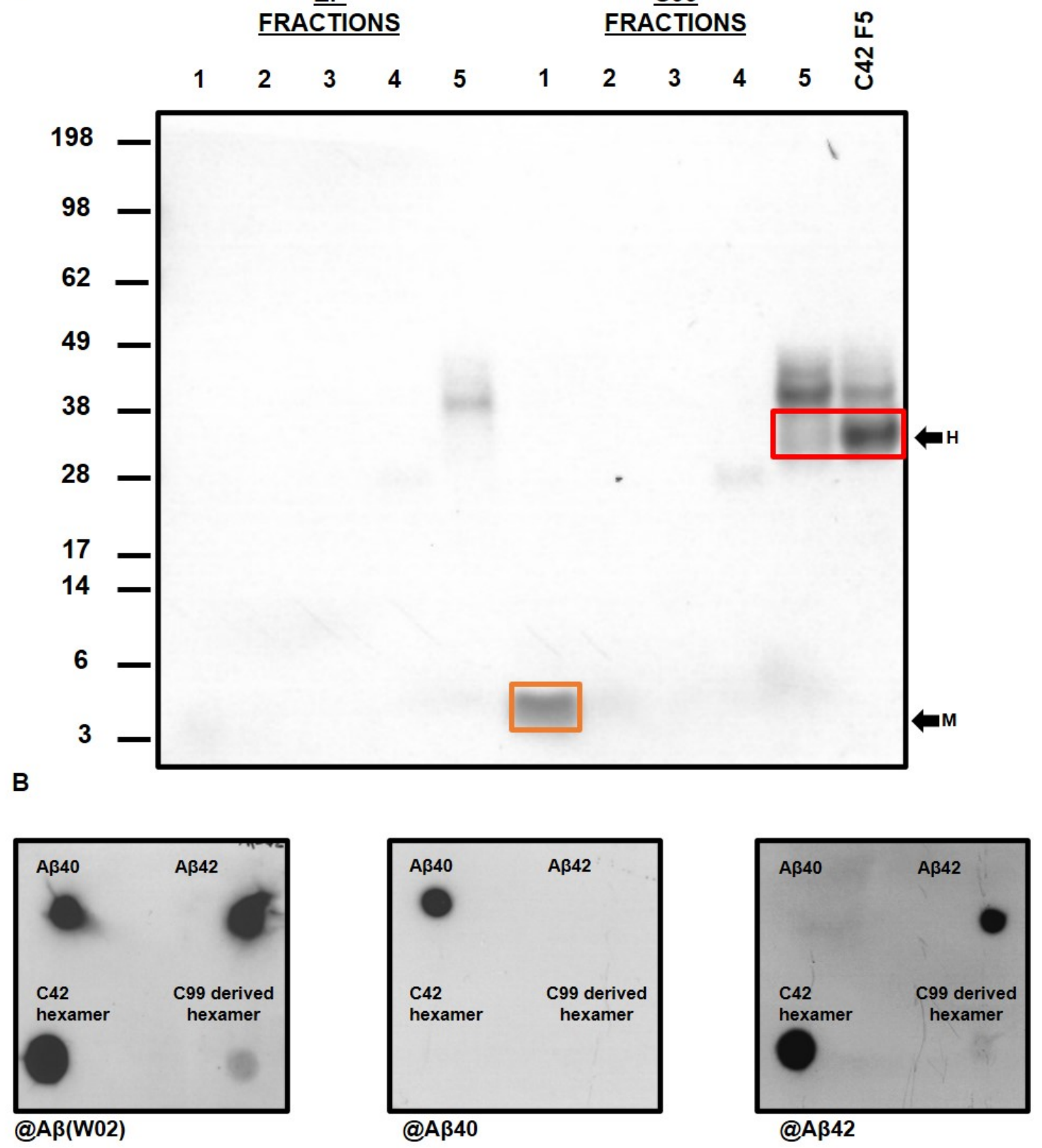

Figure 2. Isolation of $A \beta$ assemblies and identification of hexameric assembly $A \beta$ isoform. 


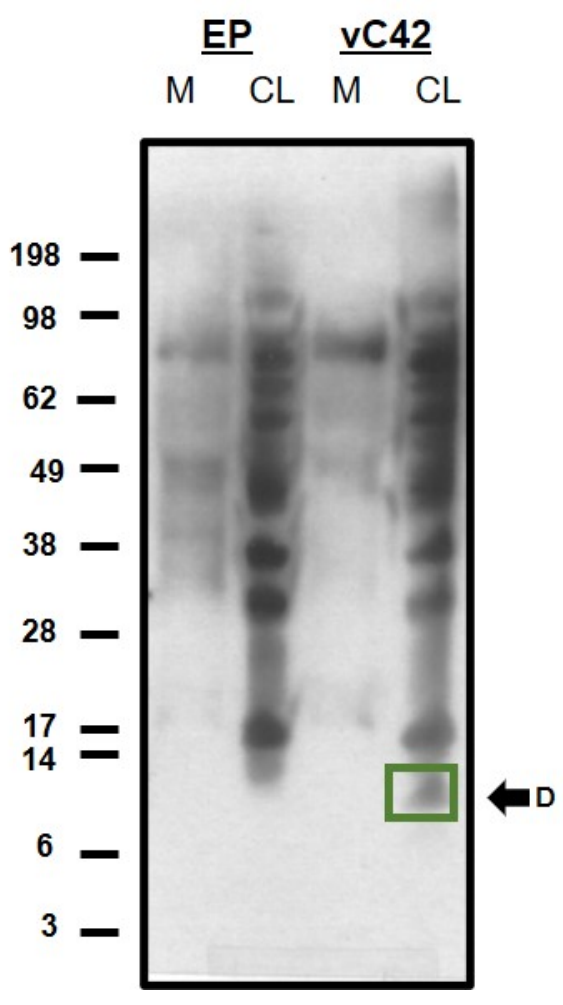

Figure 3. Hexamer formation is directly related to $A \beta 42$ self-assembly propensity 
A

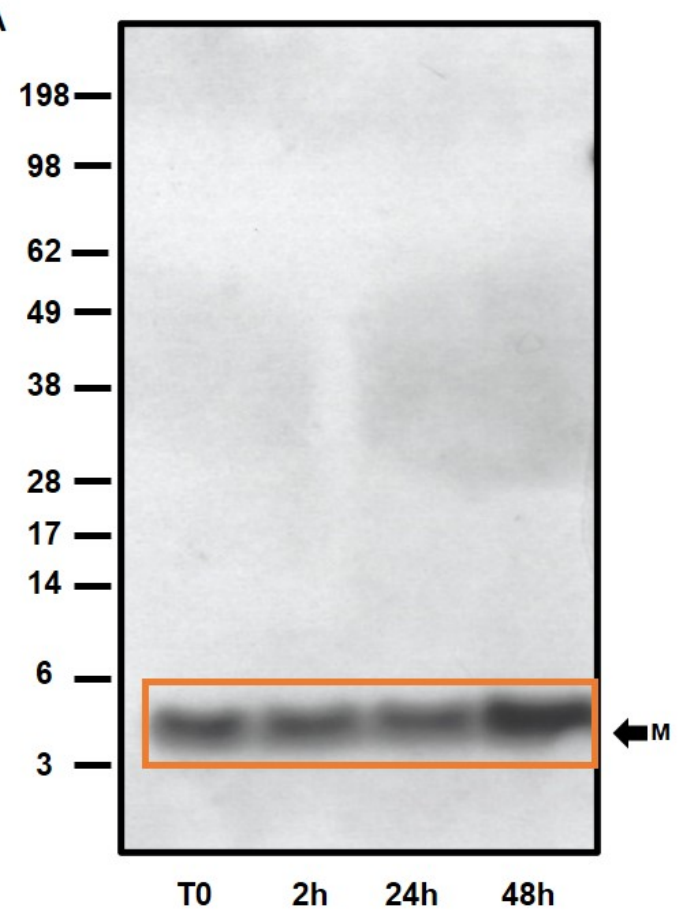

B

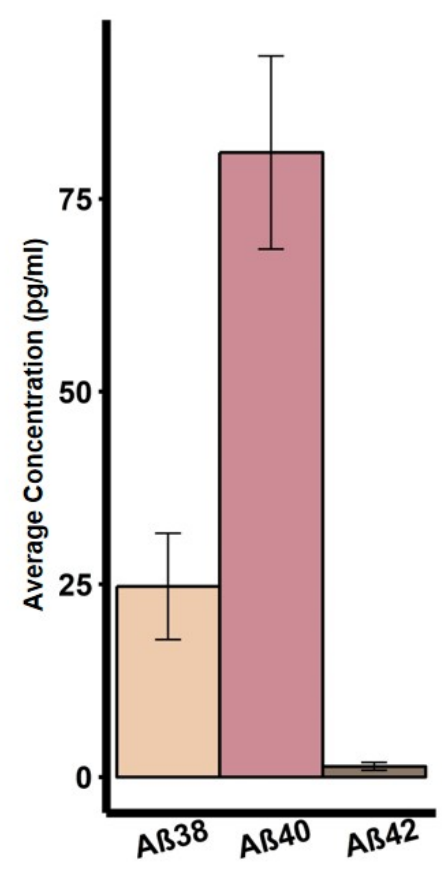

C

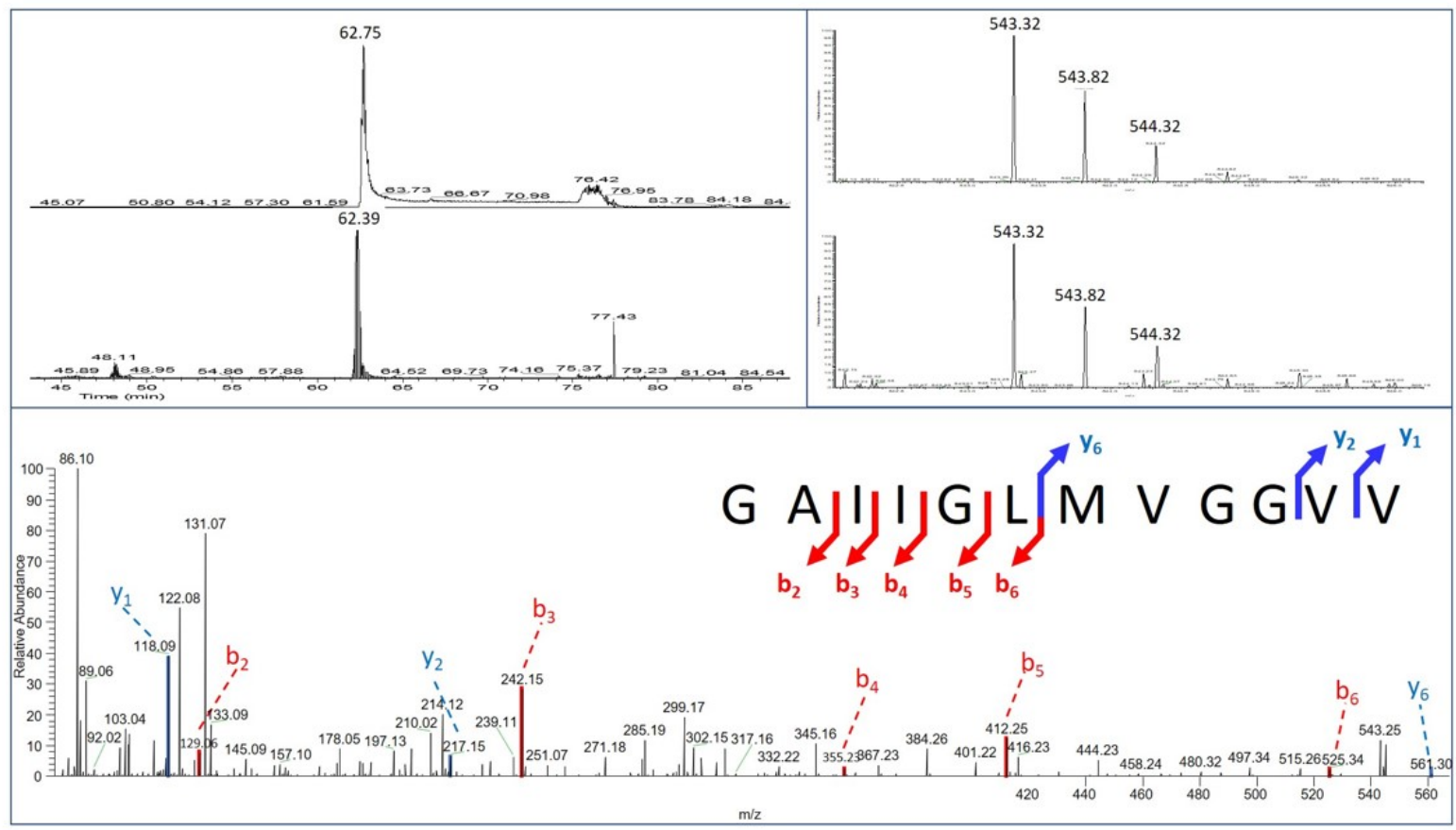

Figure 4. Hexamer formation is directly related to Aß42 primary sequence. 
A
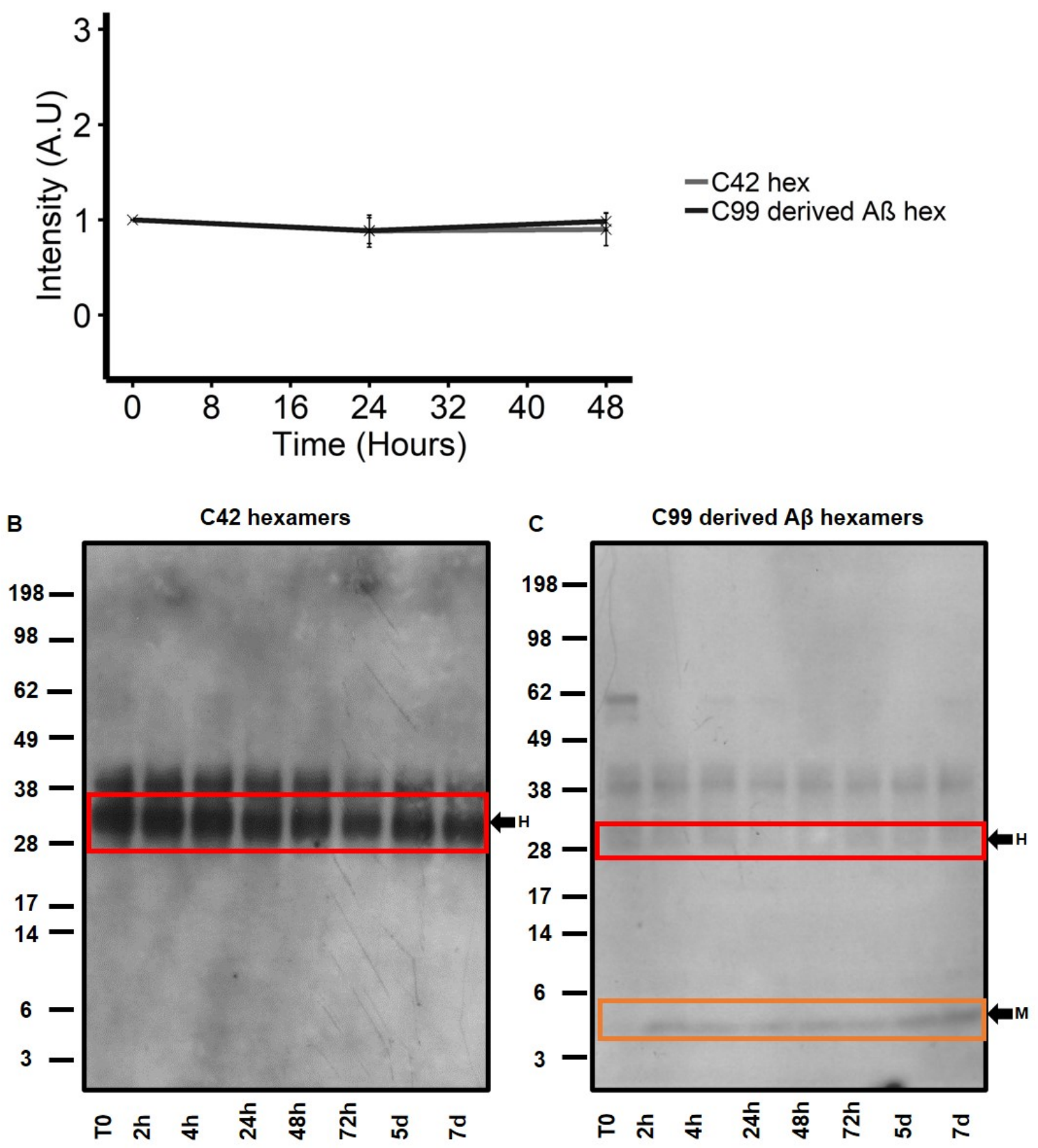

Figure 5. Isolated hexameric A $\beta$ does not self-assemble into higher molecular weight assemblies. 

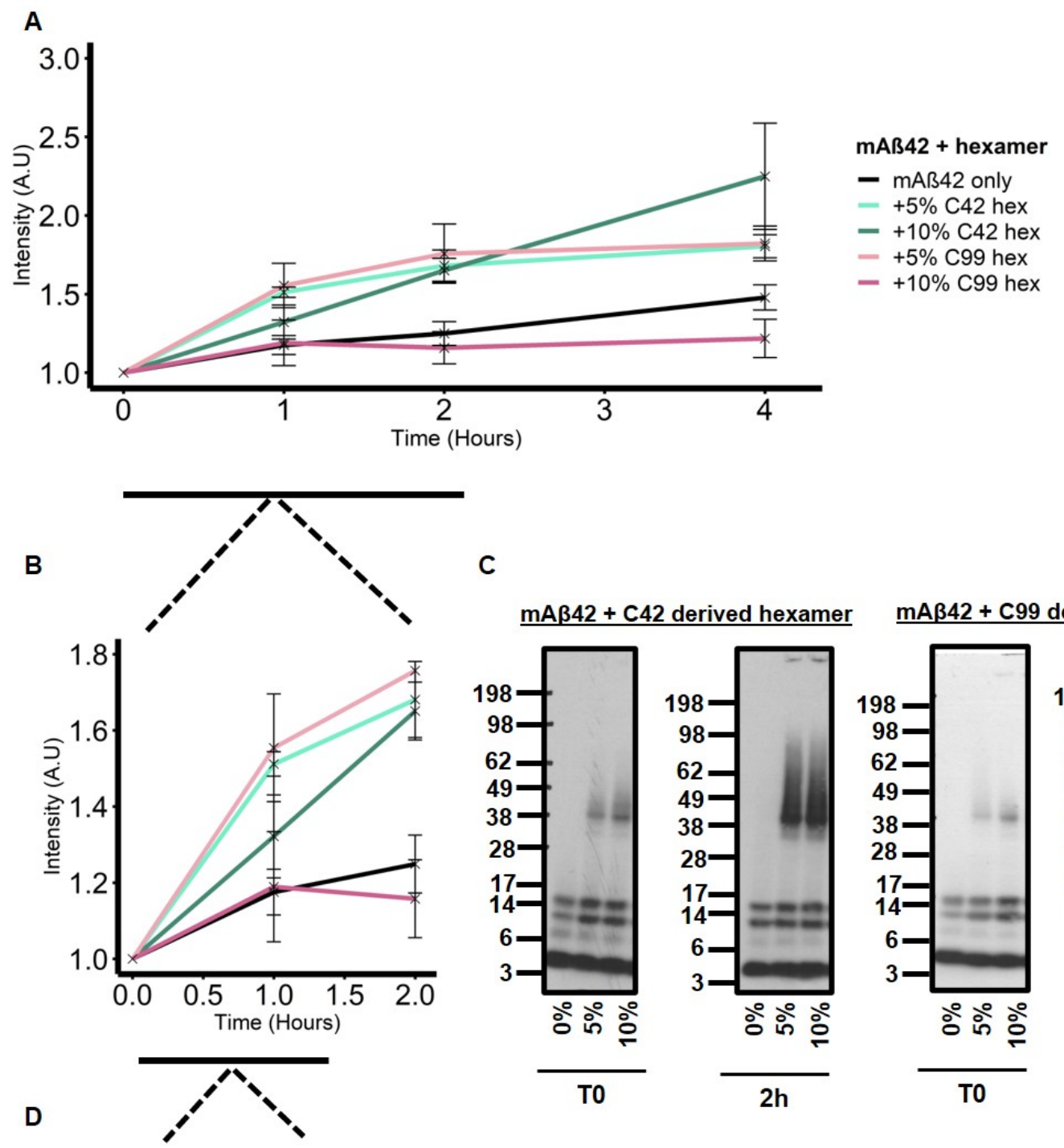

C

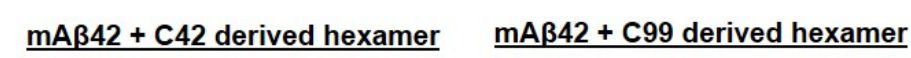
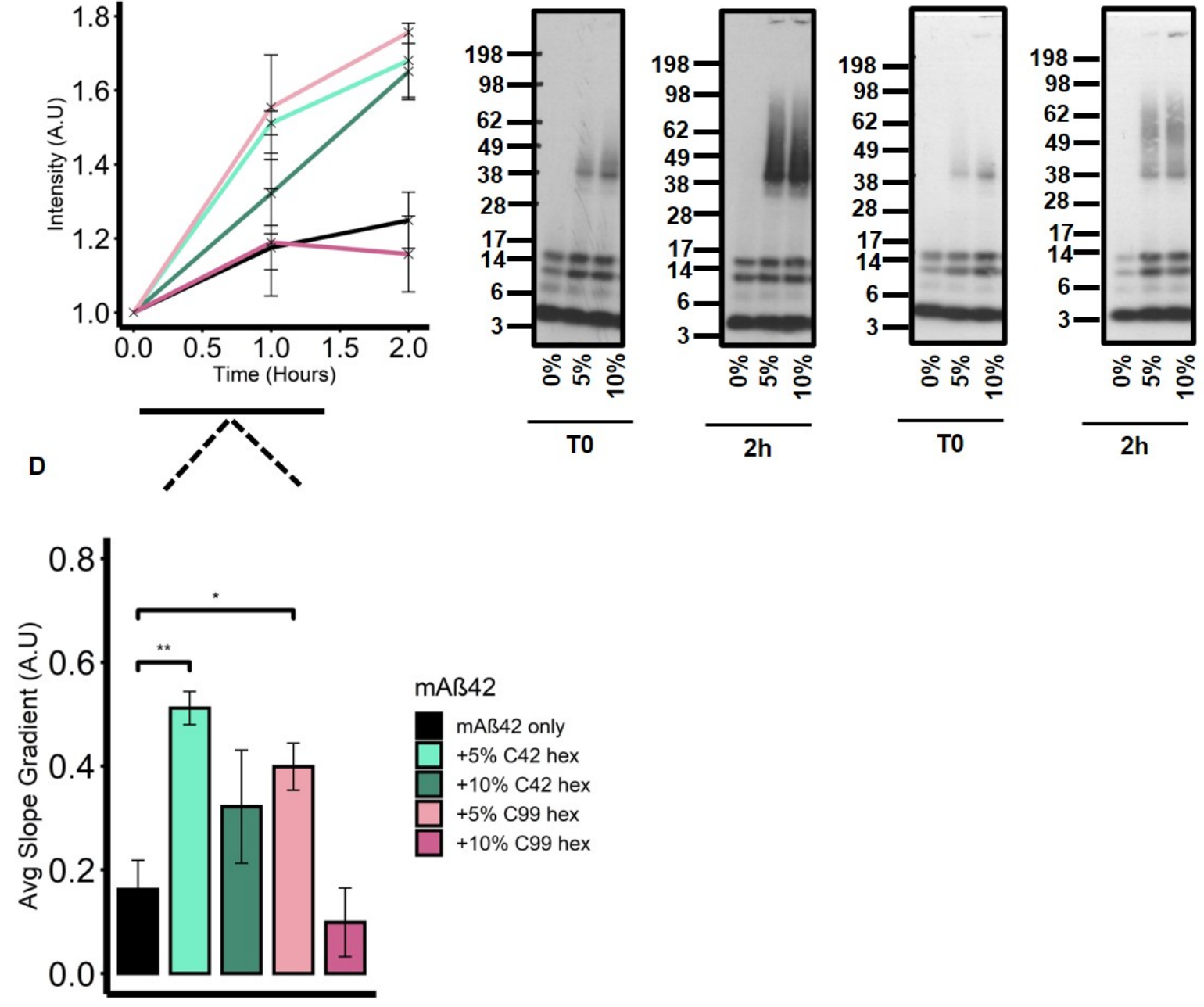

Figure 6. Isolated $\mathrm{C} 42$ and $\mathrm{C} 99$ derived hexameric $\mathrm{A} \beta$ nucleate monomeric $\mathrm{A} \beta 42$ (mAß42). 
A
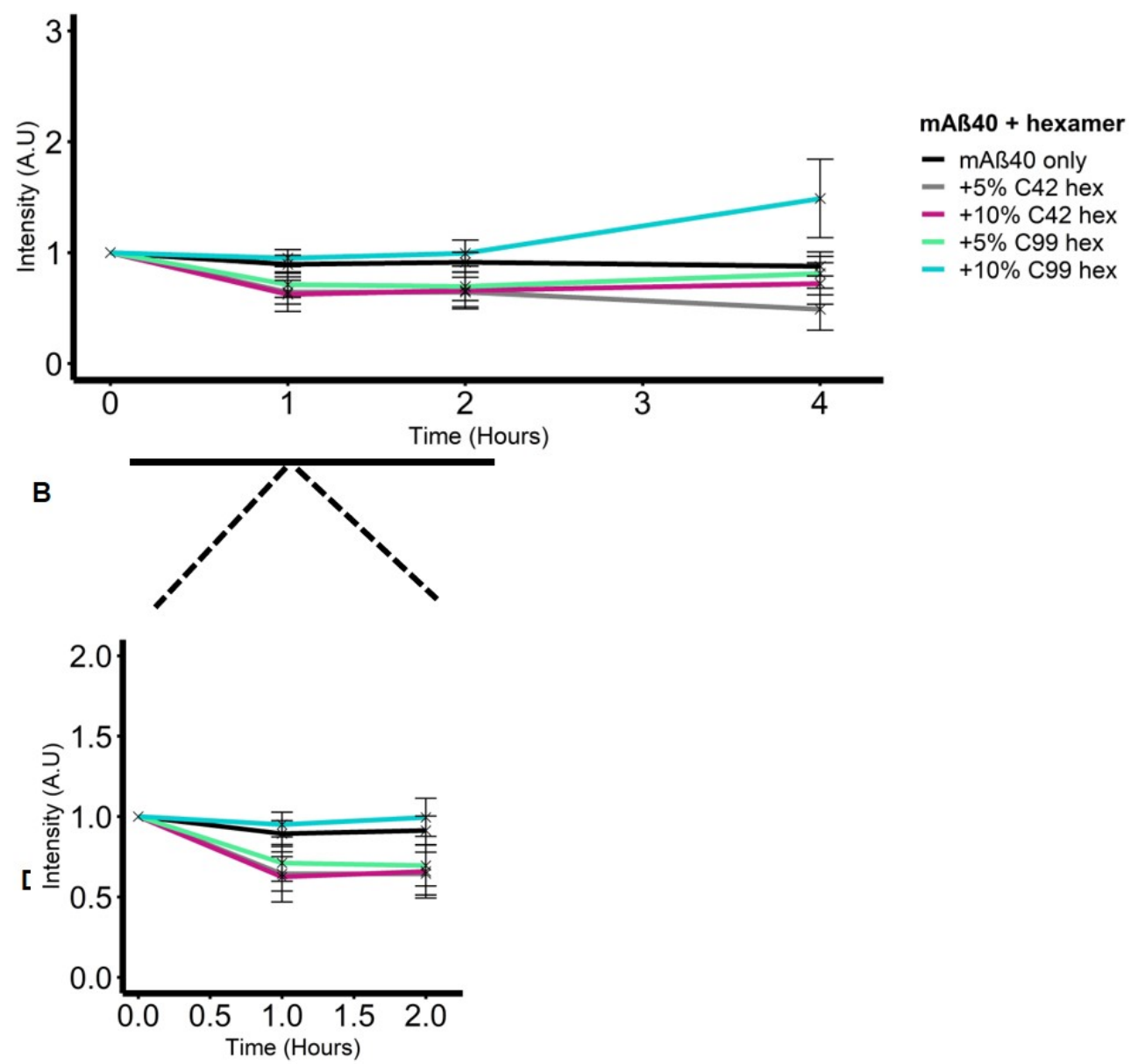

C $\underline{\mathrm{mA} \beta 40+\mathrm{C} 42 \text { derived hexamer }}$ $\underline{\mathrm{mA} \beta 40+\mathrm{C} 99 \text { derived hexamer }}$
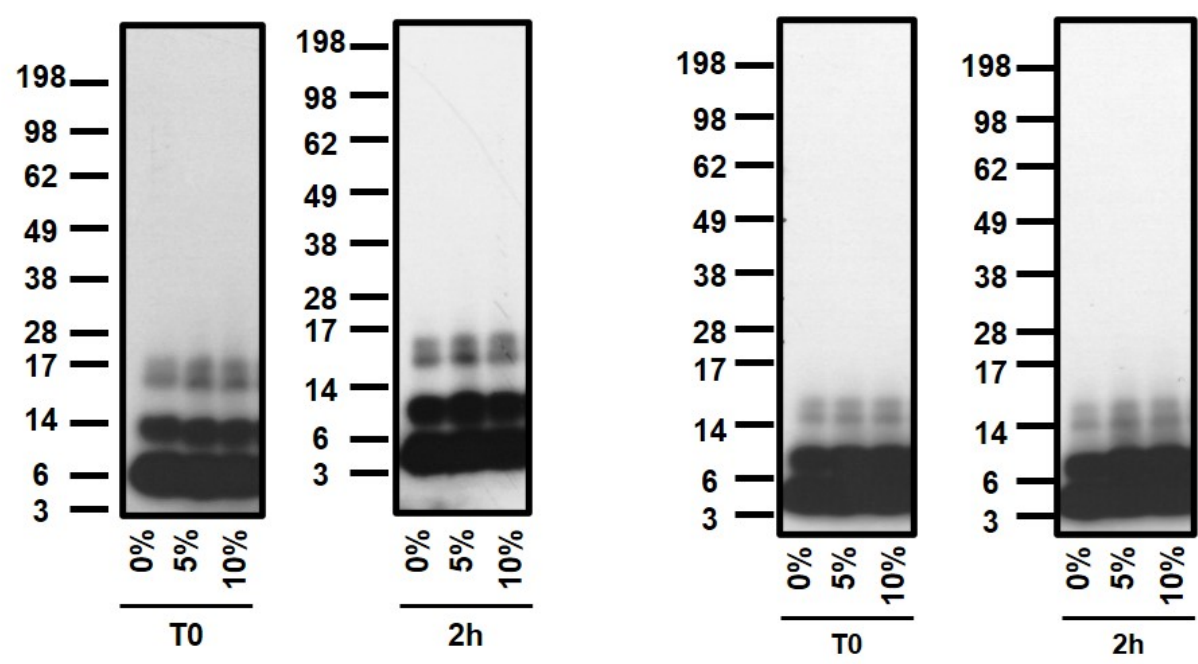

Figure 7. Isolated C42 and C99 derived hexameric Aß do not readily nucleate monomeric $\mathrm{A} \beta 40$ (mA $\beta 40)$. 
Figures
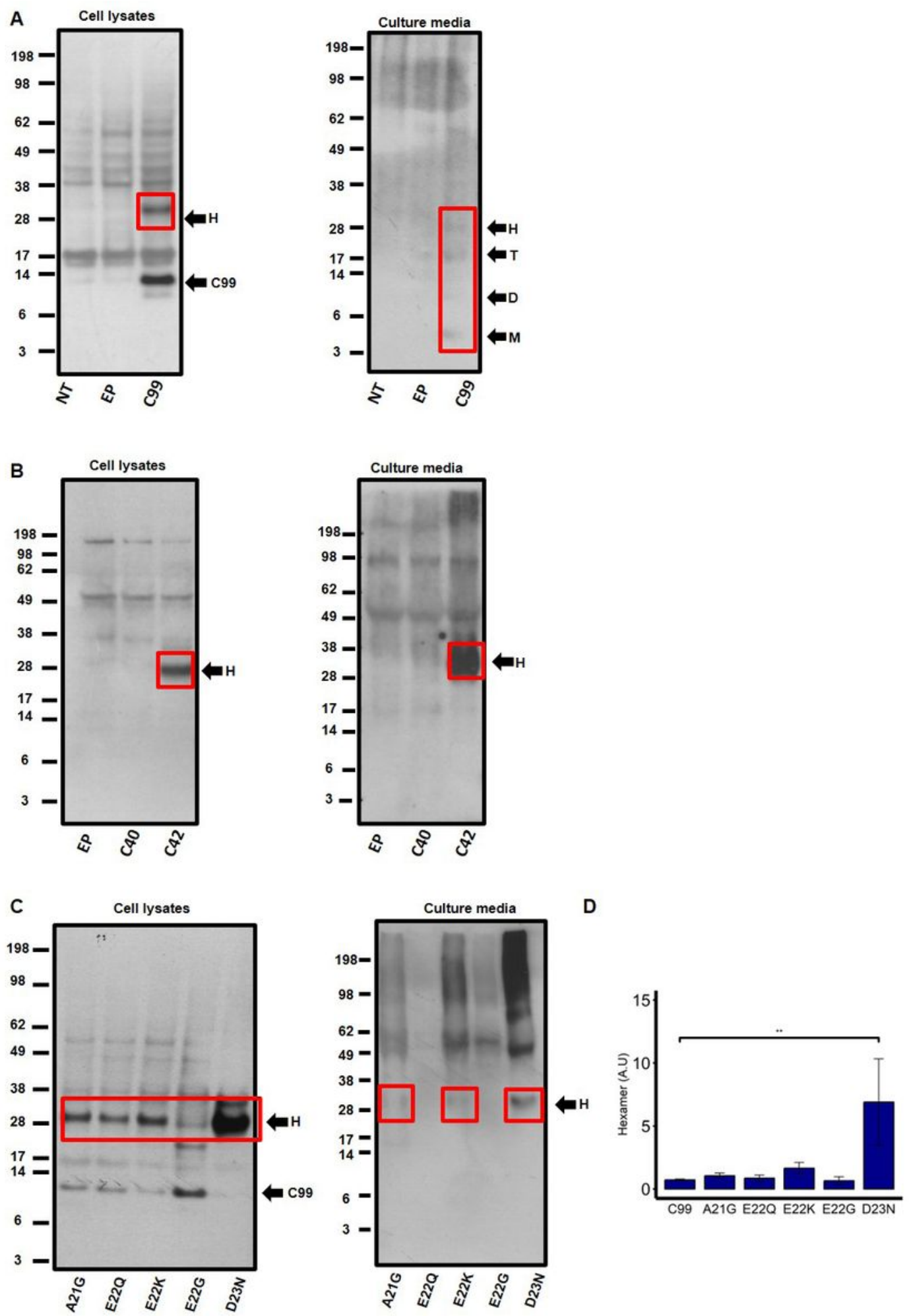

Figure 1

$\mathrm{A} \beta$ profile in transfected $\mathrm{CHO}$ cells detected with the anti-A $\beta$ WO-2 antibody. (A) Hexamer formation (red box) is seen in cell lysates of $\mathrm{CHO}$ cells transfected with $\mathrm{C} 99$ (right panel). Monomers (M), Dimers (D), Trimers $(\mathrm{T})$ and Hexamers $(\mathrm{H})$, were detected in the culture media of $\mathrm{C} 99$ transfected $\mathrm{CHO}$ cells (left 
panel). (B, right panel) No assemblies were detected in the cell lysates of $\mathrm{C} 40$ transfected $\mathrm{CHO}$ cells, however, hexameric $A \beta$ was detected in cell lysates of $\mathrm{C} 42$ transfected $\mathrm{CHO}$ cells. (B, left panel)

Hexameric $A \beta$ is also detected in culture media of $\mathrm{CHO}$ cells transfected with $\mathrm{C} 42$ only. (C) Hexameric $A \beta$ is detected in cell lysates and media of $\mathrm{CHO}$ cells transfected with FAD mutations in the $\mathrm{C} 99$ sequence. (D) Hexamer formation was quantified on the C99 signal (black arrow) for each of the mutations. The D23N (lowa) mutation showed a significant increase in hexamer formation (**) compared to C99. Oneway ANOVA with Tukey's post hoc comparison where $p=<0.01(*),<0.001(* *),<0(* \star *)$. Error bars are expressed as \pm SEM $(\mathrm{N}=3)$. 
A EP

FRACTIONS

C99

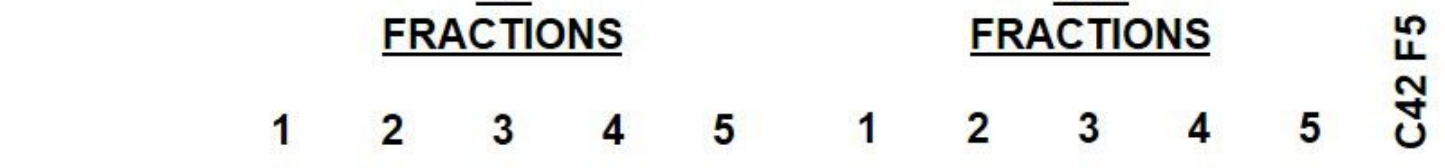

198

$-$

98

62

49

$38-$

$28-$

17

14

1. 2 
from $\mathrm{C} 42$ transfected $\mathrm{CHO}$ cells. (B) Dot blotting was carried out to identify the hexameric $A \beta$ isoform using the WO-2, anti-A $\beta 40$ and anti-A $\beta 42$ antibodies. Synthetic $A \beta 40$ and $A \beta 42$ were used as positive controls. Both $\mathrm{C} 42$ and $\mathrm{C} 99$ derived $A \beta$ hexamers are detected by the anti-A $\beta$ W0-2 antibody (left panel) and anti-A 342 antibody (right panel), however, not by the anti-A $\beta 40$ antibody (middle panel) confirming the hexamers are composed of $A \beta 42$.

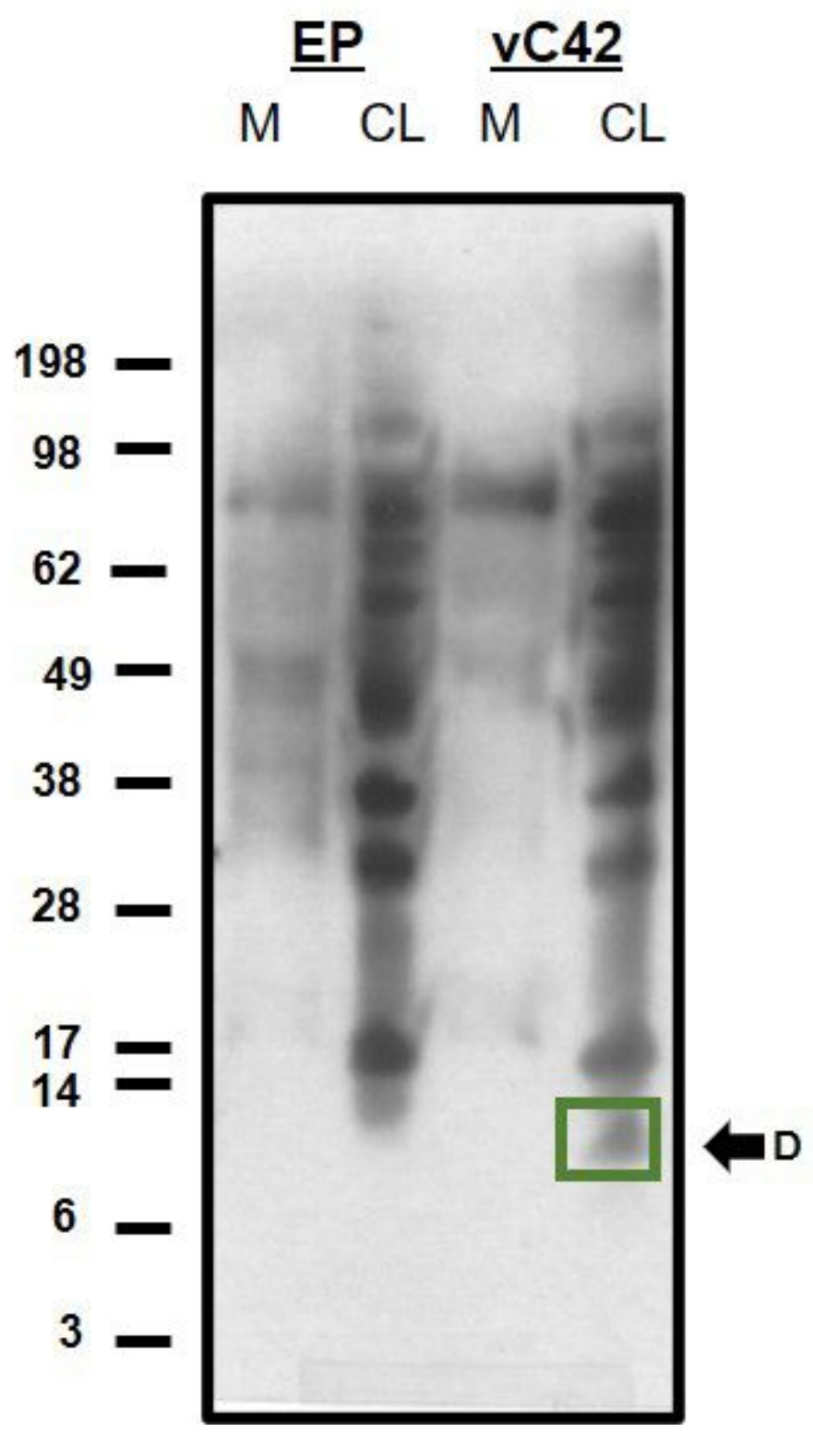

Figure 3

Hexamer formation is directly related to $A \beta 42$ self-assembly propensity. $\mathrm{CHO}$ cells transfected with vC42 (F19S, G37D), did not form hexameric $A \beta$ in either the cell lysates or media detected by the W0-2 antibody. However, dimers (green box) were detected in the cell lysates of vC42 transfected CHO cells. 
A

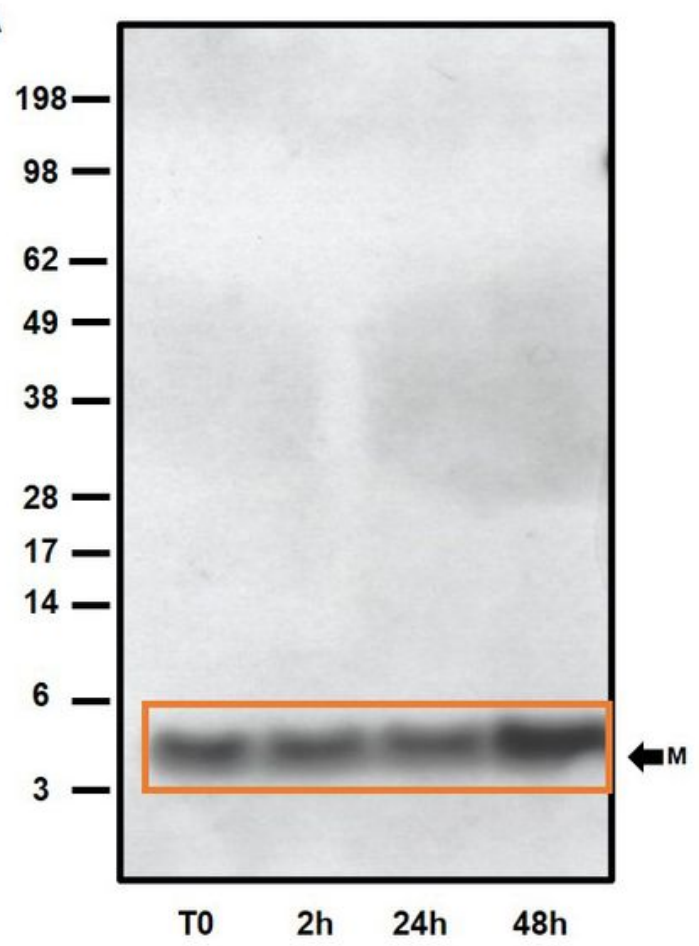

B

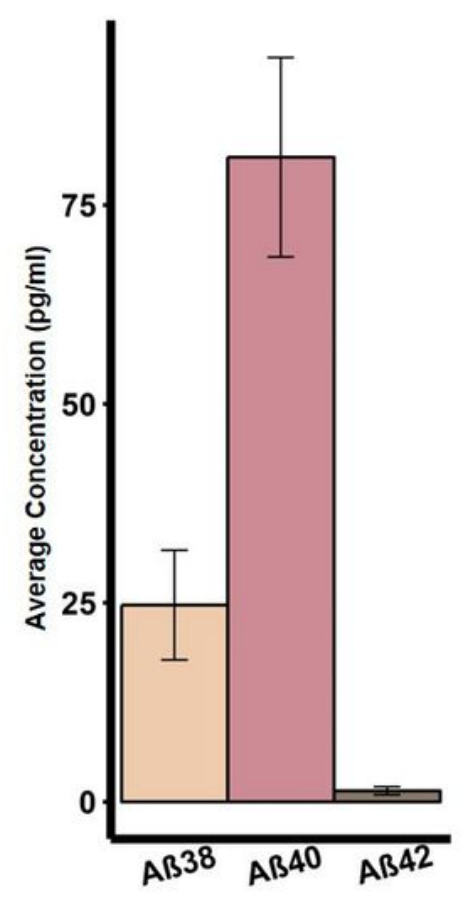

C

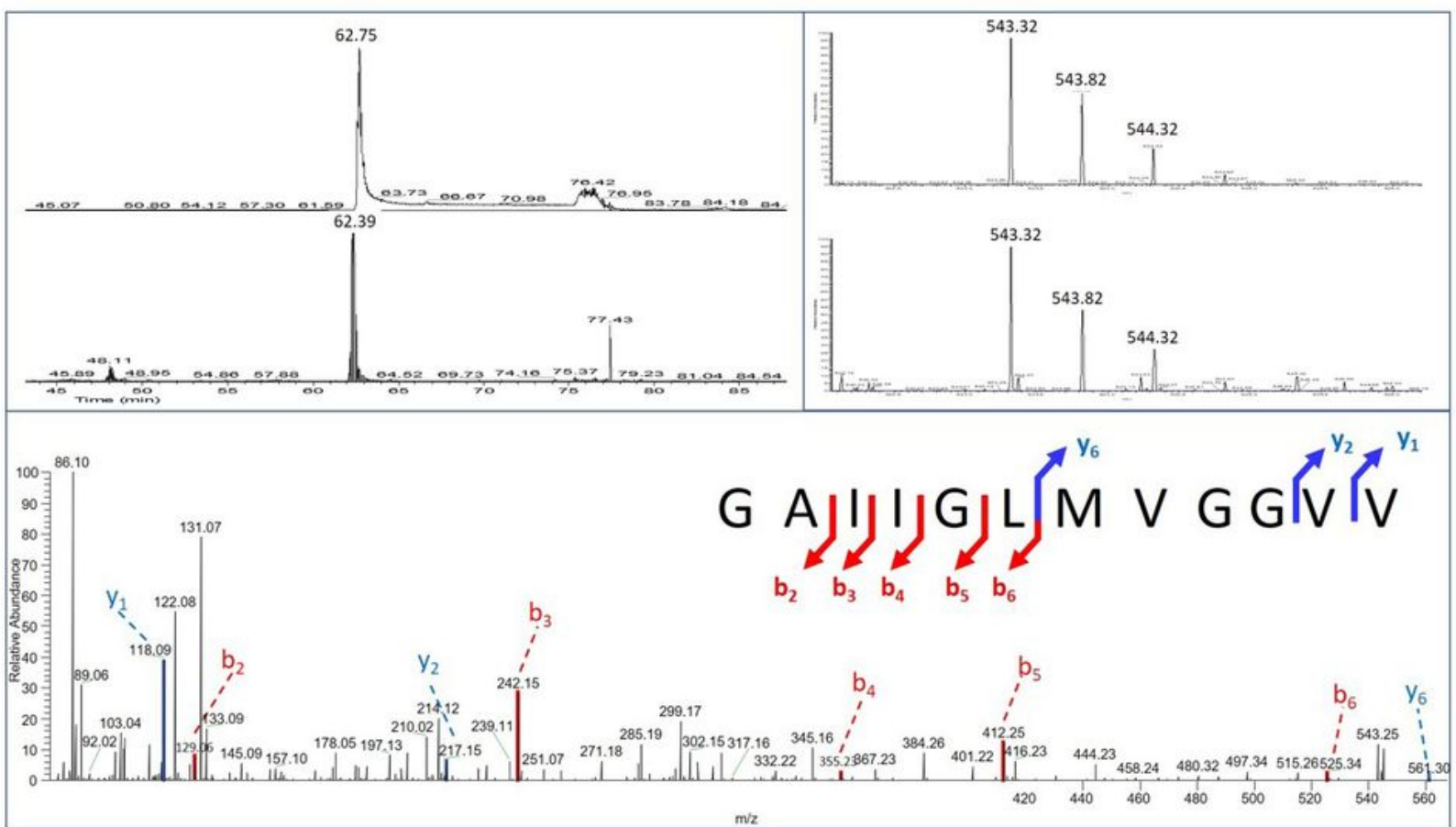

Figure 4

Hexamer formation is directly related to $A \beta 42$ primary sequence. $(A)$ Isolated monomeric $A \beta$ incubated at room temperature over $48 \mathrm{hrs}$ does not assemble into hexameric or other higher molecular weight assemblies as assessed by western blotting detected with the W0-2 antibody. (B) ECLIA measurements $(\mathrm{N}=5)$ on the media of $\mathrm{C} 99$ transfected $\mathrm{CHO}$ cells identified $\mathrm{A} \beta 40$ as the most abundant monomeric $A \beta$ isoform $(80.9 \mathrm{pg} / \mathrm{ml})$. Low concentrations of $A \beta 38(24.7 \mathrm{pg} / \mathrm{ml})$ and even lower concentrations of $A \beta 42$ 
$(1.3 \mathrm{pg} / \mathrm{ml})$ were detected in this culture media (C) CLC-MS/MS identification of A 340 in the C99 Sample. Top left panel: extracted ion chromatogram of the $[\mathrm{M}+2 \mathrm{H}] 2+$ detected at 62 minutes, for the standard (top) and the $\mathrm{C} 99$ sample (bottom). Top right Panel: mass spectra of the A 340 fragment ion showing the isotopic pattern for the standard (top) and the C99 sample (bottom). Bottom panel: MS/MS annotated spectrum characterising an Aß40 fragment from the C99 sample.

A
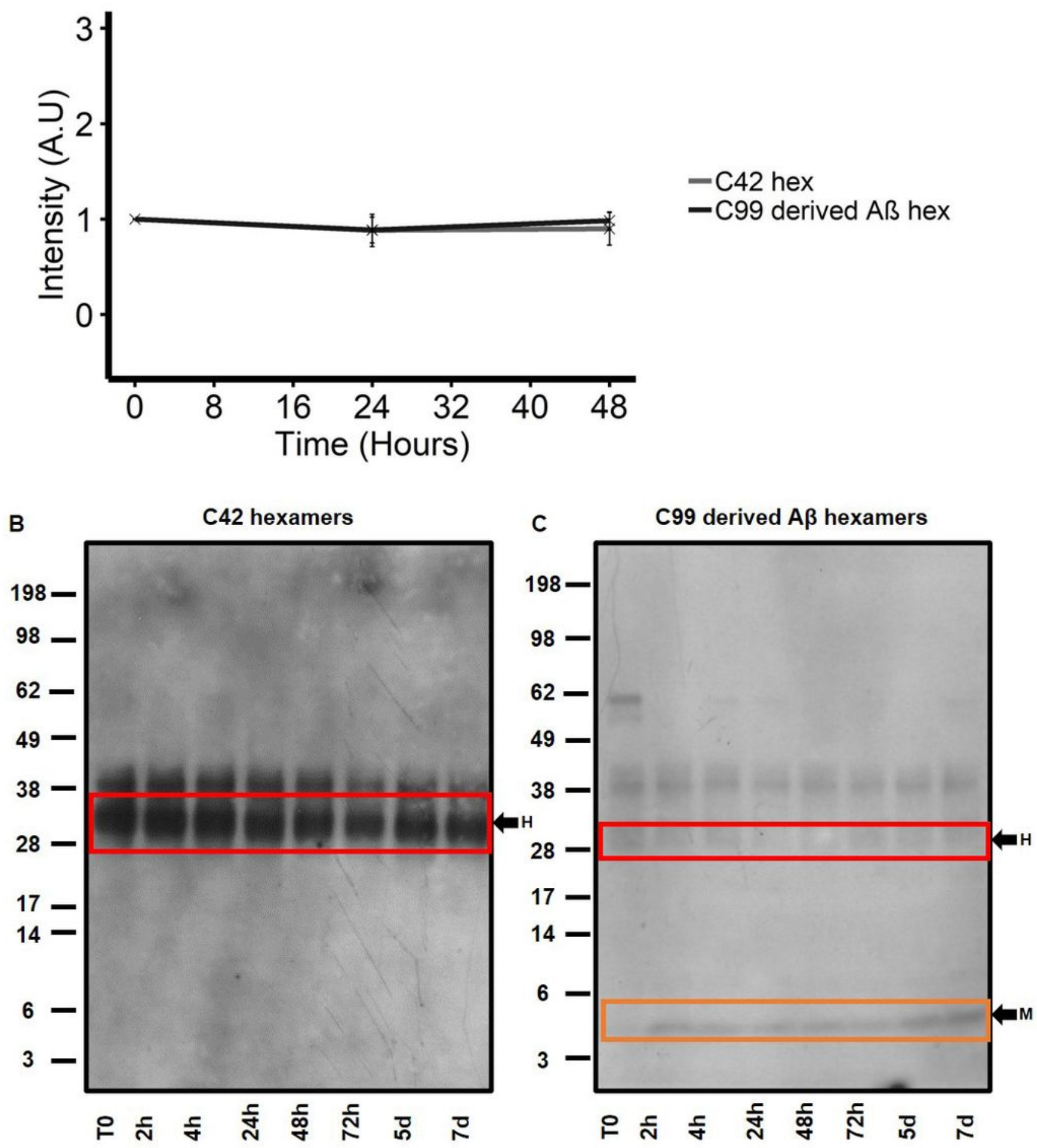

Figure 5 
Isolated hexameric $A \beta$ does not self-assemble into higher molecular weight assemblies (A) $150 \mu \mathrm{M}$ isolated hexameric $A \beta$ from $C 42$ and $\mathrm{C} 99$ transfected $\mathrm{CHO}$ cells was incubated with $20 \mu \mathrm{M}$ ThT and fluorescence was monitored over $48 \mathrm{hrs}$ as a measure of fibrillogenesis. No increase in fluorescence was seen for either of the isolated hexamers. (B and $C$ ) Western blotting and detection with the W0-2-antibody revealed both hexamers (red box) do not assemble into higher molecular weight assemblies over 7days. Hexamers from $\mathrm{C} 99$ transfected $\mathrm{CHO}$ cells, do, however disassemble into monomers (orange box) over time as was detected from 2 hrs onwards.
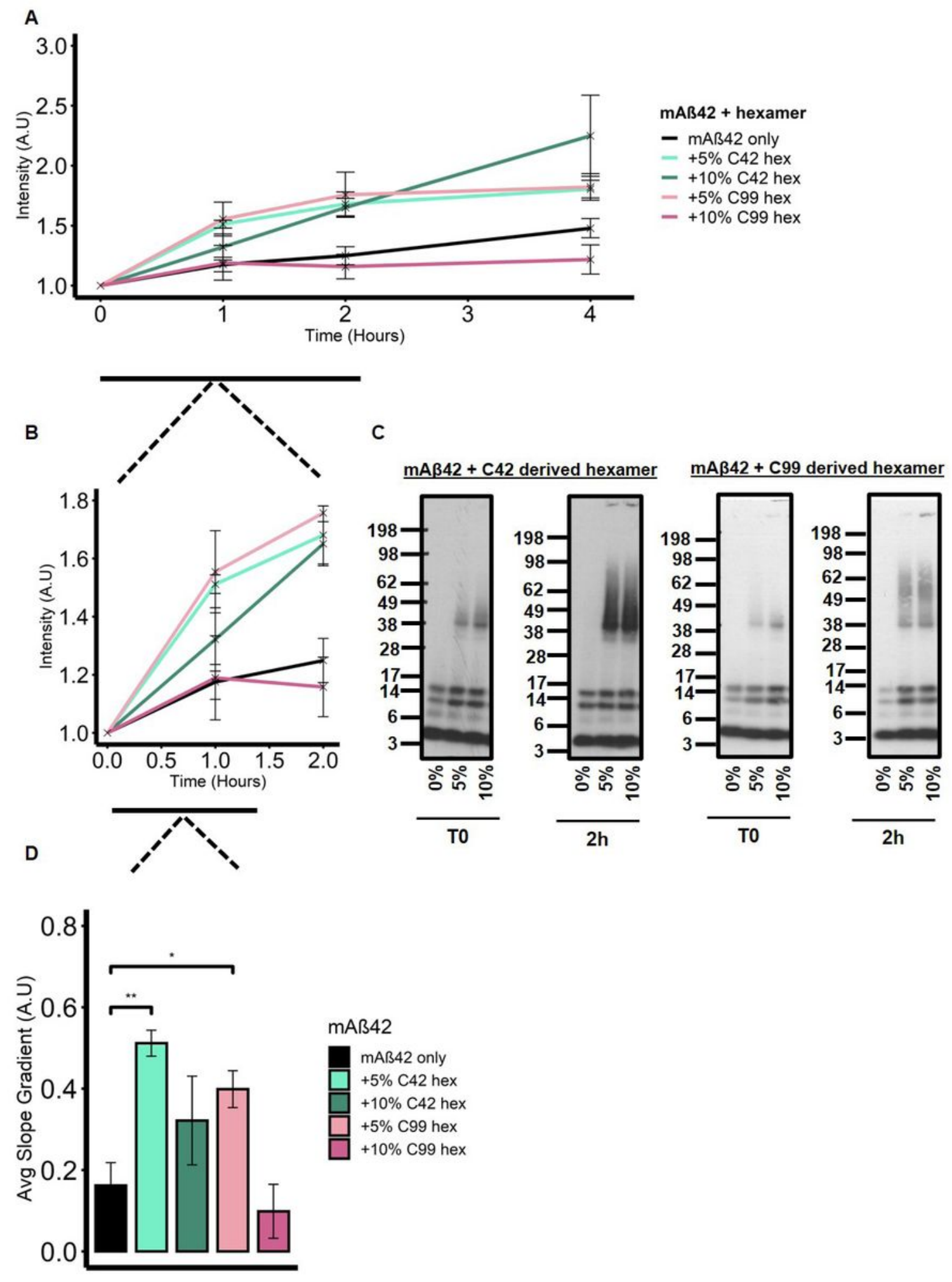


\section{Figure 6}

Isolated $\mathrm{C} 42$ and $\mathrm{C} 99$ derived hexameric $A \beta$ nucleate monomeric $A \beta 42$ (mAß42). (A) $50 \mu \mathrm{M}$ mAß42 was seeded with 5 - or $10 \%$ hexamer and the solution was the incubated with $20 \mu \mathrm{M}$ ThT. Fluorescence was monitored over 24 hours. (B) Addition of both 5- and 10\% C42 hexamer results in an immediate increase in ThT fluorescence (0-2 hours). (C) Western blotting with the W0-2 antibody revealed all seeding conditions form higher molecular weight assemblies at T0 and by $2 \mathrm{hrs}$ fibrils are seen 'stuck' in the wells of the gel. (D) The gradient of the ThT fluorescence slope was calculated at the early time points of aggregation (0-1 hour) and One-way ANOVA with Tukey's post hoc comparison where $p=<0.01\left({ }^{*}\right),<$ $\left.0.001{ }^{(* *}\right),<0(* \star *)$, revealed addition of $5 \%$ C42 hexamer significantly $(* *)$ increased the kinetics of aggregation compared to $\mathrm{mA \beta 42}$ only as did the addition of $5 \% \mathrm{C} 99$ derived hexamer $\left({ }^{*}\right)$. Error bars are expressed as $\pm S E M$. 

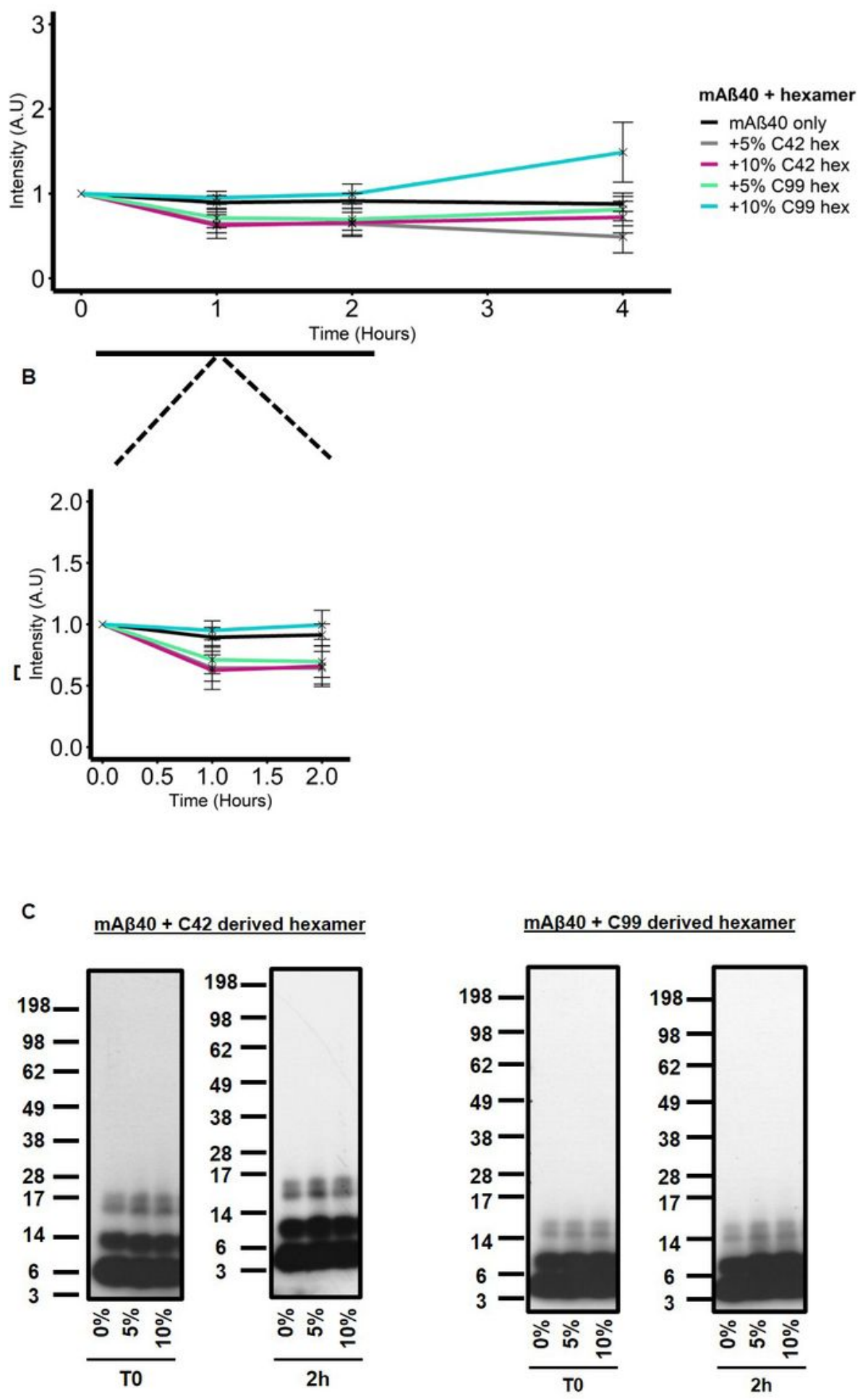

Figure 7

Isolated C42 and C99 derived hexameric A $\beta$ do not readily nucleate monomeric $A \beta 40$ (mAß40). (A) $50 \mu M$ mA 340 was seeded with 5 - or $10 \%$ hexamer and the solution was then incubated with $20 \mu \mathrm{M}$ ThT. Fluorescence was monitored over 4 hours. (B) Addition of both 5- and 10\% did not result in an increased fluorescence at early time points (0-2 hourss) (C) Western blotting detected with the W0-2 antibody 
revealed seeding conditions with both hexamers does not lead to the formation of higher molecular weight assemblies compared to $\mathrm{mA} \beta 40$ only.

\section{Supplementary Files}

This is a list of supplementary files associated with this preprint. Click to download.

- VadukuletalSupplementalData.pdf 